\title{
Polymeric nanoparticles conjugate a novel heptapeptide as an epidermal growth factor receptor-active targeting ligand for doxorubicin
}

This article was published in the following Dove Press journal:

International Journal of Nanomedicine

28 August 2012

Number of times this article has been viewed

\section{Chia Wen Liu',2 \\ Wen Jen Lin'}

'Graduate Institute of Pharmaceutical Sciences, College of Medicine, National Taiwan University, Taipei; ${ }^{2}$ Drug Delivery Department, Biomedical Engineering Research Laboratories, Industrial Technology Research Institute, Hsinchu, Taiwan

Correspondence: Wen Jen Lin F 12, I Jen Ai Rd Sec I, Graduate Institute of Pharmaceutical Sciences, College of Medicine, National Taiwan University, Taipei 100, Taiwan

Tel +886223123456 ext 88396

Fax +886223916126

Email wjlin@ntu.edu.tw
Background: This study was performed to develop a functional poly(D,L-lactide-co-glycolide)poly(ethylene glycol) (PLGA-PEG)-bearing amino-active end group for peptide conjugation.

Methods and results: PLGA was preactivated following by copolymerization with PEG diamine. The resulting amphiphilic PLGA-PEG copolymer bearing $97.0 \%$ of amino end groups had a critical micelle concentration of $3.0 \times 10^{-8} \mathrm{~mol} / \mathrm{L}$, and the half-effective inhibition concentration $\left(\mathrm{IC}_{50}\right)$ of the prepared PLGA-PEG nanoparticles was $>100 \mathrm{mg} / \mathrm{mL}$, which was much higher than that of PLGA nanoparticles $(1.02 \pm 0.37 \mathrm{mg} / \mathrm{mL})$. The amphiphilic properties of PLGA-PEG spontaneously formed a core-shell conformation in the aqueous environment, and this special feature provided the amino group on the PEG chain scattered on the surface of PLGA-PEG nanoparticles for efficient peptide conjugation. The peptide-conjugated PLGA-PEG nanoparticles showed three-fold higher uptake than peptide-free PLGA-PEG nanoparticles in a SKOV3 cell line with high expression of epidermal growth factor receptor. Both peptideconjugated and peptide-free PLGA-PEG nanoparticles were used as nanocarriers for delivery of doxorubicin. Although the rate of release of doxorubicin from both nanoparticles was similar, drug release at $\mathrm{pH} 4.0$ (500 U lipase) was faster than at $\mathrm{pH}$ 7.4. $\mathrm{The}_{\mathrm{IC}}$ of doxorubicin-loaded peptide-conjugated PLGA-PEG nanoparticles in SKOV3 cells $(0.05 \pm 0.03 \mu \mathrm{g} / \mathrm{mL})$ was much lower (by 62.4-fold) than that of peptide-free PLGA-PEG nanoparticles $(3.12 \pm 1.44 \mu \mathrm{g} / \mathrm{mL})$. Conclusion: This in vivo biodistribution study in SKOV3 tumor-bearing mice was further promising in that accumulation of doxorubicin in tumor tissue was in the order of peptide-conjugated PLGA-PEG nanoparticles > peptide-free PLGA-PEG nanoparticles $>$ doxorubicin solution. Keywords: amphiphilic copolymer, peptide, nanoparticles, SKOV3 cell, doxorubicin

\section{Introduction}

Poly(D,L-lactic-co-glycolic acid) (PLGA) copolymers are widely used in drug delivery because of their good biocompatibility, ability to biodegrade into natural metabolites, and safety for human use. ${ }^{1,2}$ In recent decades, PLGA copolymers have been used in various medical devices and pharmaceutical dosage forms, including sutures, microparticles, nanoparticles, pellets, and implants for different types of drugs. They were approved by the US Food and Drug Administration for use in drug delivery systems, such as Lupron Depot ${ }^{\circledR}{ }^{3}$ The safety of PLGA in clinical use has been well established. ${ }^{4-7}$

Like colloidal drug delivery systems, when PLGA nanoparticles are intravenously administered, they are quickly eliminated from the systemic circulation by macrophages in the spleen and the mononuclear phagocyte system in Kupffer cells of the liver. ${ }^{8}$ Such rapid elimination limits the use of PLGA nanoparticles as drug delivery and targeting carriers. 
Thus, it is necessary to modify the PLGA nanoparticle surface so that it can escape uptake by the mononuclear phagocyte system and have a prolonged circulation time in the blood. ${ }^{9}$ This can be successfully achieved in PLGA nanoparticles when their surface is modified by hydrophilic poly(ethylene glycol) (PEG). PEG-coated nanoparticles avoid recognition by the mononuclear phagocyte system and elimination due to the shielding effect of the polymer chains in PEG. ${ }^{10}$

The biodistribution of nanoparticles is controlled mainly by their physical and biochemical properties, including particle size, the nature of the polymer and drug, and surface properties. ${ }^{11-14}$ The advantage of using nanoparticles in cancer therapy stems from the enhanced permeation and retention effect. ${ }^{15,16}$ Nanoparticles are passively targeting and accumulate in tumors via the enhanced permeation and retention effect after systemic administration. ${ }^{17-19}$ Drug concentration increases at the tumor site to improve their therapeutic efficacy and reduce nonspecific side effects. ${ }^{20,21}$ Moreover, polymeric nanoparticles have been used as an active targeting delivery system to conjugate a ligand for targeting to specific cancer cells. ${ }^{22-25}$ These ligands can be small molecules, proteins, antibodies, or peptides which bind specifically to cancer cells and provide an efficient and safe nanocarrier for drug delivery. ${ }^{26-29}$ Proteins and antibodies have a large molecular weight and bind to receptors with a steric structure and with high affinity. However, foreign antibodies are produced with biological methods, exhibit variations from batch to batch, and easily induce an unexpected immune response. The peptides are smaller than antibodies and can bind to receptors specifically, and rarely induce an immune response. Peptides are chemically synthesized on a large scale and the quality is more stable from batch to batch. Thus, using peptides as ligands can overcome the limitations of antibodies and enable them to retain their active targeting ability. The epidermal growth factor (EGF) receptor is highly expressed in human epithelial cancer cells, including breast, ovarian, and lung cancer. ${ }^{30-32}$ The EGF receptor is recognized as an important target for the development of treatment for cancer. Several EGF-targeting therapeutic agents, including cetuximab $\left(\right.$ Erbitux $^{\circledR}$ ) and erlotinib (Tarceva ${ }^{\circledR}$ ), have already been approved by the US Food and Drug Administration. ${ }^{33}$ Kolonin et al identified 17 peptides that mimic EGF receptor ligands, including amphiregulin, heparin-binding EGF-like growth factor, and epiregulin. ${ }^{34}$ We further selected the NR7 peptide (NSVRGSR) based on alignment of the tripeptide motif with the EGF binding domain, and the NR7 peptide was the only peptide which not only appeared twice between these EGF receptor ligands but also contained tripeptide motifs relative to the mature EGF domain among these 17 peptides. ${ }^{35}$
The purpose of this study was to apply the core-shell conformation of the amphiphilic PLGA-PEG copolymer bearing amino-active end groups for peptide conjugation. The amphiphilic PLGA-PEG copolymer was synthesized by copolymerization of the preactivated PLGA-NHS with PEG diamine. The physicochemical properties of the resulting amphiphilic PLGA-PEG copolymer bearing amino end groups were characterized by ${ }^{1} \mathrm{H}-\mathrm{NMR}$, and the yield, PEGylation efficiency, molecular weight, and critical micelle concentration were determined. PLGA-PEG nanoparticles were prepared using the solvent evaporation method, and their size, zeta potential, morphology, and cell viability were characterized. The NR7 peptide was selected as a peptide ligand to conjugate with our synthesized amphiphilic PLGA-PEG copolymer. Two approaches were investigated to prepare the peptide-conjugated PLGA-PEG nanoparticles. One was to conjugate the peptide with the amphiphilic PLGA-PEG copolymer followed by preparation of nanoparticles. The other was to conjugate the peptide with previously prepared PLGA-PEG nanoparticles exhibiting micelle core-shell conformation. The peptide conjugation ratios and performance of the peptide-conjugated nanoparticles were determined and characterized. The cellular uptake efficiency was evaluated in SKOV3 cells expressing high levels of the EGF receptor. Doxorubicin was used as the model anticancer drug. The doxorubicinloaded peptide-free and peptide-conjugated PLGA-PEG nanoparticles were characterized, and their SKOV3 cell growth inhibition efficiency and in vitro release at physiological pH 7.4 and simulated lysosomal pH 4.0 (500 U lipase) were investigated. Finally, an in vivo biodistribution study was performed in SKOV3 tumor-bearing mice.

\section{Materials and methods Materials}

PLGA 50:50 (RG 503H, molecular weight 28 kDa, $[\eta]=0.32-0.44 \mathrm{dL} / \mathrm{g}$ ) was purchased from Boehringer Ingelheim (Ingelheim, Germany). PEG diamine ( $\mathrm{NH}_{2}$-PEG$\mathrm{NH}_{2}$; molecular weight $5 \mathrm{kDa}$ ) was from Laysan Bio Inc(Arab, AL). Ethyl-3-(3-dimethylaminopropyl) carbodiimide hydrochloride (EDC) and pyrene were obtained from Tokyo Chemical Industry Co, Ltd (Tokyo, Japan). The NHS was from Acros Organics (Geel, Belgium). An L929 mouse fibroblast cell line and a SKOV3 human ovarian cancer cell line were purchased from the Bioresource Collection and Research Center (Hsinchu, Taiwan). Dulbecco's modified Eagle's medium, McCoy's 5A medium, and fetal bovine serum were obtained from Biological Industries (Kibbutz 
Beit Haemek, Israel). 5-Carboxyfluorescein and 6-carboxyfluorescein succinimidyl ester (fluorescein-NHS) and fluorescein isothiocyanate (FITC) were from Pierce (Rockford, IL). Peptide-fluorescein (NSVRGSR, peptide-FTIC, 95\% purity) was synthesized by Kelowna International Scientific Inc (Taipei, Taiwan). glycol monomer. The PEGylation efficiency was calculated by equation (2). ${ }^{37}$

$$
\begin{aligned}
& \text { Yield }(\%) \\
& =\frac{\text { Weight of PLGA-PEG }}{\text { Weight of PLGA-NHS and PEG diamine }} \times 100 \%
\end{aligned}
$$

\section{Synthesis of amphiphilic PLGA-PEG copolymer}

PLGA was preactivated before PEGylation with PEG diamine, and the reaction procedure is shown in Scheme 1.28 Briefly, PLGA polymer $5 \mathrm{~g}(178.5 \mu \mathrm{mol})$ was dissolved in $20 \mathrm{~mL}$ of dichloromethane. Subsequently, NHS $135 \mathrm{mg}$ (1172.2 $\mu \mathrm{mol})$ and EDC $230 \mathrm{mg}(1198.3 \mu \mathrm{mol})$ were added to the PLGA solution and the mixture was reacted at $22^{\circ} \mathrm{C}$ for 16 hours under a nitrogen atmosphere. The preactivated PLGA-NHS was precipitated with ether and centrifuged at $4000 \mathrm{rpm}$ for 5 minutes at room temperature. The residue was washed three times with an ice-cold mixture of an equal volume of ether and methanol. The PLGA-NHS obtained was dried in a desiccator under vacuum and stored at $-20^{\circ} \mathrm{C}$. For synthesis of PLGA-PEG, PLGA-NHS $750 \mathrm{mg}(26.7 \mu \mathrm{mol})$ was dissolved in $4 \mathrm{~mL}$ of dichloromethane, and $\mathrm{PEG}$ diamine $133 \mathrm{mg}(26.6 \mu \mathrm{mol})$ was added to the solution. The mixture was stirred at $22^{\circ} \mathrm{C}$ for 24 hours. The synthesized PLGA-PEG copolymer bearing the amino end group was precipitated with ice-cold methanol and centrifuged at $4000 \mathrm{rpm}$ for 5 minutes at room temperature. The precipitate was washed three times with ice-cold methanol to remove unreacted PEG diamine. The PLGA-PEG copolymer bearing the amino end group was further purified by precipitation in cold methanol following by drying in a desiccator and storage at $-20^{\circ} \mathrm{C}$.

\section{Characterization of PLGA-PEG amphiphilic copolymer}

The yield of PLGA-PEG copolymer was calculated by equation (1). ${ }^{36}$ The PLGA-PEG copolymer was characterized by ${ }^{1} \mathrm{H}-\mathrm{NMR}\left(400 \mathrm{mHz}, \mathrm{CDCl}_{3}\right.$ ) at $\delta 5.30-5.17 \mathrm{ppm}$ for the $\mathrm{CH}$ of lactide, at $\delta 4.90-4.56 \mathrm{ppm}$ for the $\mathrm{CH}_{2}$ of glycolide, at $\delta$ 3.61-3.55 ppm for the $\mathrm{CH}_{2}$ of ethylene glycol, and at $\delta 1.62-1.45 \mathrm{ppm}$ for the $\mathrm{CH}_{3}$ of lactide. There were six and four protons in each D,L-lactide-co-glycolide and ethylene
The molecular weight of the polymer was determined by gel permeation chromatography with a refractive index detector (RI 2031 Plus, Jasco, Tokyo, Japan) and a Styragel ${ }^{\circledR}$ HR 4E column $(7.8 \times 300 \mathrm{~mm}$, Waters, Milford, MA). The mobile phase was chloroform, the flow rate was set at $1 \mathrm{~mL}$ per minute, and the temperature was maintained at $35^{\circ} \mathrm{C}$. Polymers were dissolved in chloroform, and filtered through a $0.2 \mu \mathrm{m}$ syringe filter prior to injection. The molecular weight of PLGA-PEG was determined using polystyrene standards. The critical micelle concentration of PLGA-PEG copolymer-induced micelle formation was determined using a fluorescence spectrophotometer (SpectraMax Gemini XS, Mississauga, ON, Canada) and a pyrene as a fluorescence probe. The emission wavelength was set at $390 \mathrm{~nm}$, and the excitation fluorescence was recorded at $336 \mathrm{~nm}$ and $333 \mathrm{~nm}$. The critical micelle concentration value was determined from the plot of the ratio of $\mathrm{I}_{336} / \mathrm{I}_{333}$ versus logarithmic concentrations of PLGA-PEG copolymer. The concentration at the intersection of the horizontal and the steep parts of the curve corresponded to the critical micelle concentration value. ${ }^{38,39}$

\section{Synthesis of PLGA-PEG-FITC copolymer}

The procedure for synthesis of the PLGA-PEG-FITC copolymer is shown in Scheme 2A. PLGA-PEG $27.7 \mathrm{mg}$ (2 $\mu \mathrm{mol})$ was dissolved in $1 \mathrm{~mL}$ of dimethyl sulfoxide, and various amounts of FITC $(1,5,10,15$, and $20 \mathrm{mg}[2,10,20$, 30 , and $40 \mu \mathrm{mol}]$ ) were added into the solution separately. The mixture was stirred at room temperature in the dark for 2 hours. The molar feed ratio of PLGA-PEG: FITC 1:20 was further stirred for 4,6 , and 24 hours to investigate the effect of reaction time on conjugation of fluorescein. The PLGA-PEG-FITC synthesized was precipitated with ice-cold methanol and centrifuged at 10,000 rpm for 10 minutes at $4^{\circ} \mathrm{C}$. The precipitate was collected and washed with ice-cold 


\section{PLGA p reactivation}

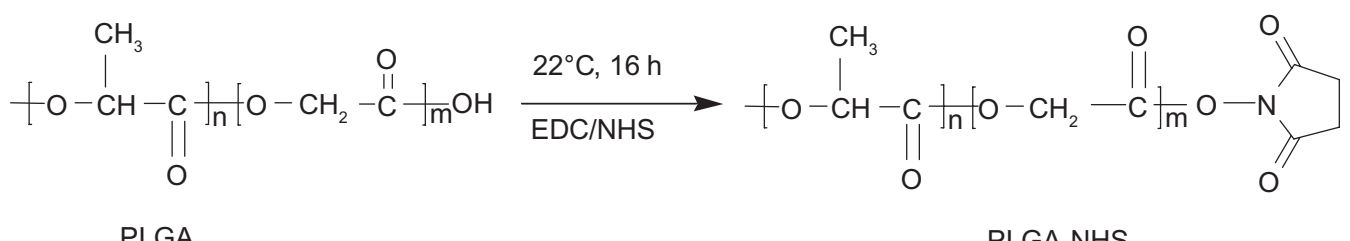

PLGA

PLGA-NHS

\section{PLGA-PEG copolymer synthesis}

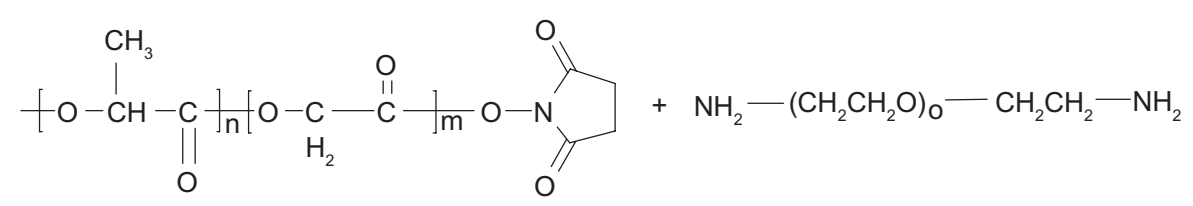

PLGA-NHS

PEG diamine

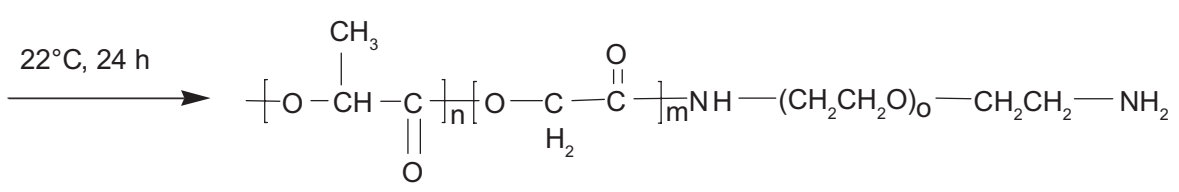

PLGA-PEG

Scheme I Synthesis of amphiphilic PLGA-PEG copolymer bearing amino-active end group.

Abbreviation: PLGA-PEG, poly(D,L-lactide-co-glycolide)-poly(ethylene glycol).

methanol three times followed by drying in the desiccator under vacuum. The obtained FITC-conjugated PLGA-PEGFITC copolymers were stored at $-20^{\circ} \mathrm{C}$. The amount of fluorescein conjugated was determined using a fluorescence plate reader (SpectraMax Gemini XS) at an excitation wavelength of $485 \mathrm{~nm}$ and an emission wavelength of $538 \mathrm{~nm}$. The fluorescein conjugation molar ratio was calculated by equation (3)..$^{40}$

Conjugation molar ratio $(\%)=\frac{\text { Mole of fluorescein }}{\text { Mole of copolymer }} \times 100 \%$

\section{Preparation of nanoparticles}

The nanoparticles were prepared using a solvent evaporation method. PLGA, PLGA-PEG, or PLGA-PEG-FITC $20 \mathrm{mg}$ was dissolved in a $1 \mathrm{~mL}$ equal volume of acetone/ dichloromethane cosolvent and mixed well. The polymer solution was added into $10 \mathrm{~mL}$ of $0.25 \%$ polyvinyl alcohol solution and sonicated at $4^{\circ} \mathrm{C}$ for 2 minutes following by magnetic stirring for 3 hours. Polyvinyl alcohol was used to stabilize the emulsion in order to form particles of relatively small size and uniform size distribution. ${ }^{41}$ The remaining organic solvent was removed by rotary evaporator under reduced pressure at $35^{\circ} \mathrm{C}$ for 3 minutes. The nanoparticles were collected after centrifugation at $14,000 \mathrm{rpm}$ at $4^{\circ} \mathrm{C}$ for 30 minutes and subsequently washed with deionized water three times. Finally, the nanoparticles were resuspended in $0.1 \mathrm{~mL}$ of deionized distilled water which contained $5 \mathrm{mg}$ of sucrose as a cryoprotectant agent, and then freeze-dried and stored at $-20^{\circ} \mathrm{C}$. The particle size and zeta potential of nanoparticles were determined by zetasizer (Nano-ZS 90 Zetasizer, Malvern Instruments, Worcestershire, UK), and the surface morphology was observed by transmission electron microscopy (Tecnai G2, FEI Company, Hillsboro, OR) at $200 \mathrm{kV}$.

\section{PLGA-PEG NP-FITC and PLGA-PEG NP-peptide-FITC nanoparticles}

Scheme 2B(I) illustrates the conjugation of FITC with previous prepared PLGA-PEG nanoparticles to form PLGA-PEG NP-FITC. Next, $15.08 \mathrm{mg}(1.09 \mu \mathrm{mol})$ of the PLGA-PEG 


\section{A}
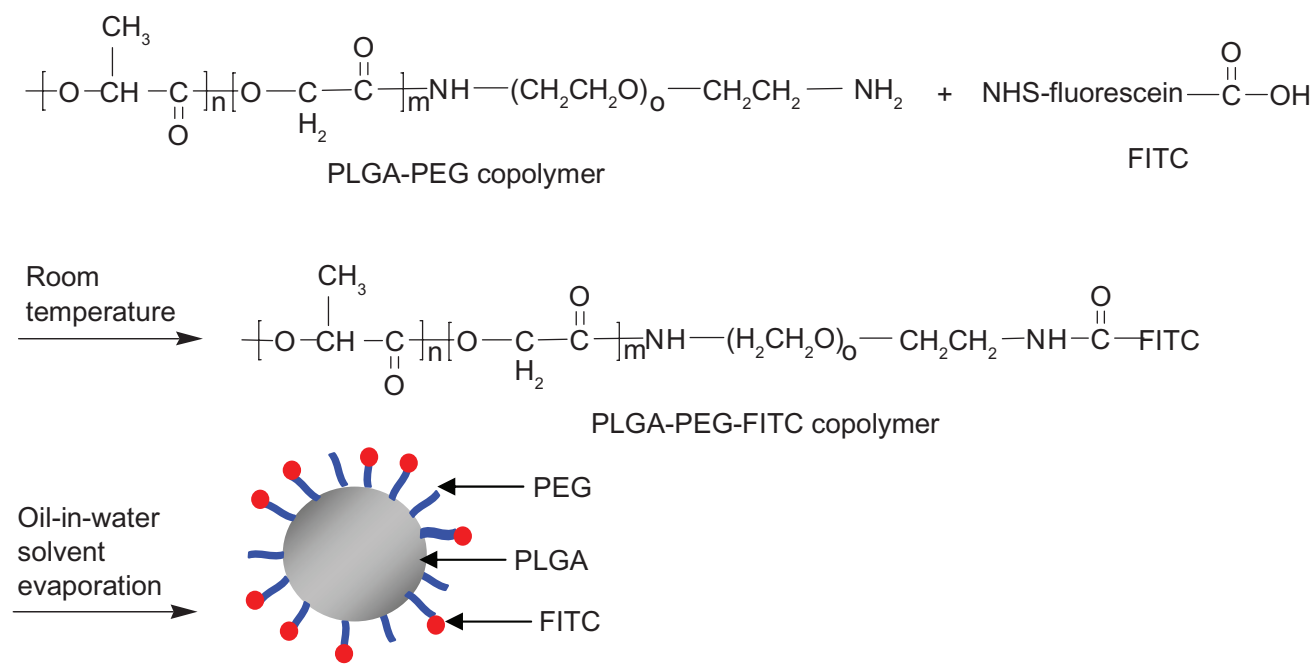

PLGA-PEG-FITC NP

\section{B}

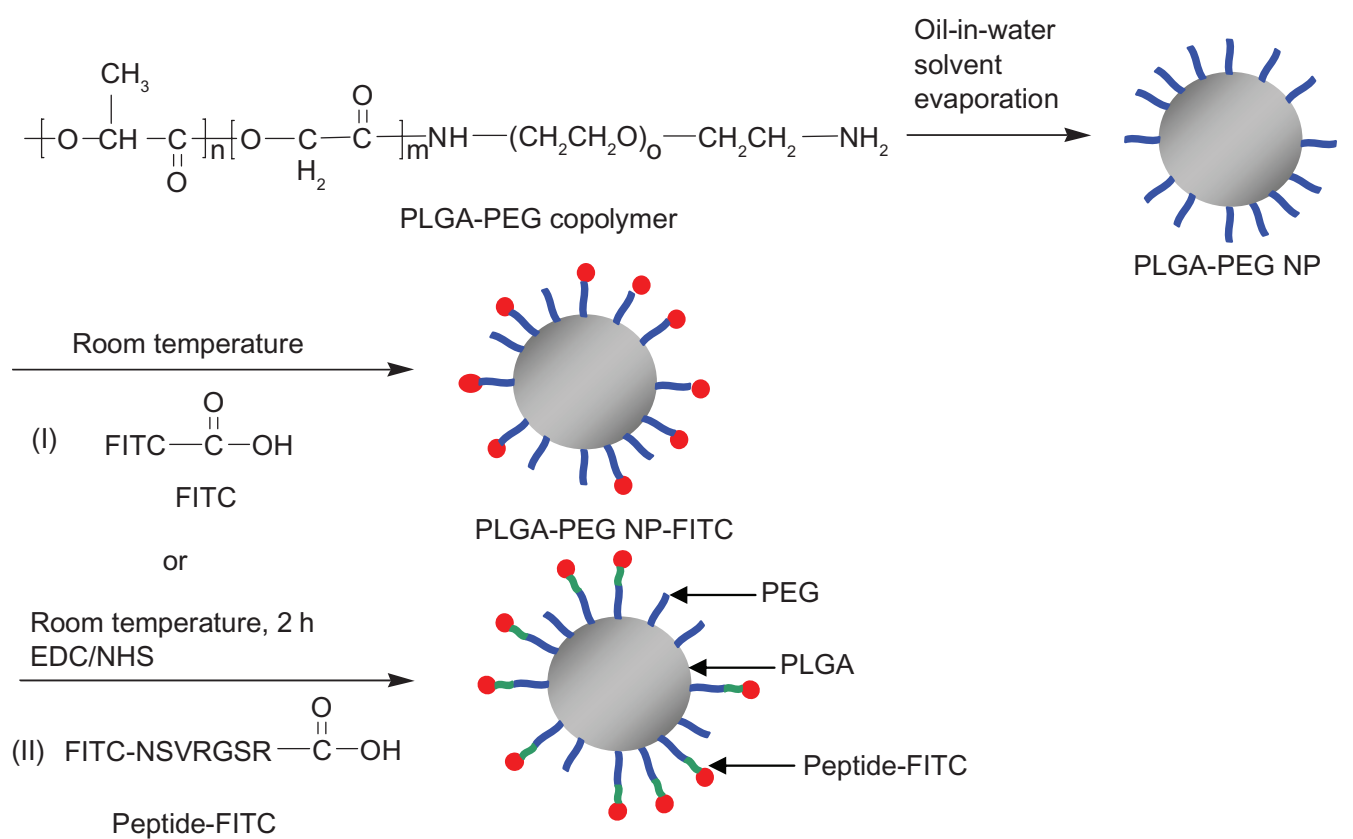

PLGA-PEG NP-peptide-FITC

Scheme 2 Synthesis of (A) PLGA-PEG-FITC and (B) PLGA-PEG NP-FITC or PLGA-PEG NP-peptide-FITC nanoparticles.

Abbreviations: PLGA, poly(D,L-lactide-co-glycolide); PEG, poly(ethylene glycol); FITC, fluorescein isothiocyanate; NP, nanoparticle; NSVRGSR, NR7 peptide; EDC, ethyl3-(3-dimethylaminopropyl) carbodiimide hydrochloride; NHS, N-hydroxysuccinimide.

nanoparticles were suspended in $0.624 \mathrm{~mL}$ of borated buffer (50 mM, pH 8.5). FITC $0.423 \mathrm{mg}(1.09 \mu \mathrm{mol})$ was added into the suspension and stirred at room temperature in the dark for 2, 4, 6, and 24 hours. A similar procedure was used to prepare PLGA-PEG NP-peptide-FITC where the carboxyl group ( $C$ terminal) of the peptide-FITC was conjugated with the amino group of PLGA-PEG nanoparticles in the presence of carbodiimide hydrochloride (EDC) and $\mathrm{N}$-hydroxysuccinimide (NHS), as shown in Scheme 2B(II). The details are as follows. The mixtures of PLGA-PEG nanoparticles $15.08 \mathrm{mg}(1.09 \mu \mathrm{mol})$, peptide-FITC $1.39 \mathrm{mg}$ $(1.09 \mu \mathrm{mol})$, NHS $0.27 \mathrm{mg}(2.2 \mu \mathrm{mol})$, and EDC $0.45 \mathrm{mg}$ 
$(2.2 \mu \mathrm{mol})$ were stirred at room temperature in the dark for 2 hours. The resulting PLGA-PEG NP-peptide-FITC was collected after centrifugation at 14,000 rpm for 30 minutes at $4^{\circ} \mathrm{C}$ and subsequently washed with deionized water three times. Finally, the nanoparticles were resuspended in $0.1 \mathrm{~mL}$ of deionized distilled water which contained $5 \mathrm{mg}$ sucrose, and then freeze-dried and stored at $-20^{\circ} \mathrm{C}$. The particle size and zeta potential were measured as described previously. The amount of conjugated FITC was determined using a fluorescence plate reader at an excitation wavelength of $455 \mathrm{~nm}$ and an emission wavelength of $523 \mathrm{~nm}$.

\section{Cellular viability study}

The cytotoxicity of PLGA and PLGA-PEG nanoparticles was studied using L929 mouse fibroblasts. L929 cells were cultured in Dulbecco's modified Eagle's medium containing $10 \%$ fetal bovine serum, $2 \mathrm{mM}$ L-glutamine, $1.5 \mathrm{~g} / \mathrm{L}$ sodium bicarbonate, and $0.1 \mathrm{mM}$ nonessential amino acids, as well as $1.0 \mathrm{mM}$ sodium pyruvate. The cells were seeded in a 96-well plate at a density of 8000 cells per well and maintained in a humidified incubator at $37^{\circ} \mathrm{C}$ in $5 \% \mathrm{CO}_{2}$ for 24 hours. The cell viability was determined using a 3-(4,5-dimethylthiazol-2yl)-2,5-diphenyl tetrazolium (MTT) assay. ${ }^{42}$ Serial dilutions of PLGA nanoparticles and PLGA-PEG nanoparticles were added in cultured medium into each well and incubated at $37^{\circ} \mathrm{C}$ for 72 hours. The medium was removed, and the cells were labeled with MTT solution and incubated at $37^{\circ} \mathrm{C}$ for 4 hours. The resulting formazan was solubilized in dimethyl sulfoxide, and the absorbance was measured using an enzyme-linked immunosorbent assay reader (Power Wave XS, BioTek, Winooski, VT) at $570 \mathrm{~nm}$. The $\mathrm{IC}_{50}$ was calculated from the plot of cell viability versus nanoparticle concentration using SigmaPlot 10.0 software. $^{43}$

\section{Cellular uptake study}

SKOV3 cells were seeded into 6-well plates at a density of $5 \times 10^{5}$ cells per well and cultured in $2 \mathrm{~mL}$ of complete McCoy's 5A medium (McCoy's 5A medium with 10\% fetal bovine serum, $2 \mathrm{mM}$ L-glutamine, $1.5 \mathrm{~g} / \mathrm{L}$ sodium bicarbonate, $0.1 \mathrm{mM}$ nonessential amino acids, and $1.0 \mathrm{mM}$ sodium pyruvate) at $37^{\circ} \mathrm{C}$ for 24 hours. The cells were then washed three times with phosphate-buffered saline, and incubated with several different fluorescein concentrations of peptidefree and peptide-conjugated PLGA-PEG nanoparticles at $37^{\circ} \mathrm{C}$ for 30 minutes. The fluorescein concentrations used for the peptide-conjugated PLGA-PEG nanoparticles were $0.27,0.82,2.47,7.4$, and $22.2 \mu \mathrm{M}$, and for peptide-free PLGA-PEG nanoparticles were 0.31, 0.94, 2.81, 8.43, and
$25.3 \mu \mathrm{M}$. The nanoparticles were removed and the cells were washed with phosphate-buffered saline three times. The cells were harvested by trypsinization and centrifuged at 1400 rpm for 5 minutes. Finally, the cells were resuspended in phosphate-buffered saline, and cellular uptake of the fluorescein-conjugated nanoparticles was measured at an excitation wavelength of $488 \mathrm{~nm}$ and an emission wavelength of $530 \mathrm{~nm}$ (FACSCalibur, Becton Dickinson, Franklin Lakes, NJ) and analyzed using BD CellQuest Pro software (version 6, Becton Dickinson). A total of 10,000 events were analyzed for each sample. The upper limit of background fluorescence was set to no more than $1 \%$ of the events with the autofluorescence controls (attributable to native cells).

\section{Preparation and characterization of doxorubicin-loaded nanoparticles}

Doxorubicin $\mathrm{HCl}(5.3 \mathrm{mg}, 9.1 \mu \mathrm{mol})$ was dissolved in $5 \mathrm{~mL}$ of water, and triethylamine $(3.1 \mathrm{mg}, 30.6 \mu \mathrm{mol})$ was added to the solution. The mixture was stirred for 24 hours at room temperature under nitrogen. Doxorubicin was extracted three times with dichloromethane. The organic layer was collected and evaporated under reduced pressure. The doxorubicin obtained was dried in a desiccator under vacuum. Doxorubicin $0.5 \mathrm{mg}$ and copolymer $20 \mathrm{mg}$ was dissolved in $1 \mathrm{~mL}$ of acetone/dichloromethane $(1 / 1, \mathrm{v} / \mathrm{v})$. This solution was slowly added to $10 \mathrm{~mL}$ of $0.25 \%$ polyvinyl alcohol solution under sonication in an ice bath for 5 minutes following stirring at room temperature for 3 hours. The remaining organic solvent was removed by rotary evaporator under reduced pressure at $35^{\circ} \mathrm{C}$ for 10 minutes. The nanoparticles were collected after centrifugation at $14,000 \mathrm{rpm}$ at $4^{\circ} \mathrm{C}$ for 30 minutes. Finally, the nanoparticles were resuspended in $0.1 \mathrm{~mL}$ of deionized distilled water containing $5 \mathrm{mg}$ sucrose as a cryoprotectant agent, then freeze-dried and stored at $-20^{\circ} \mathrm{C}$. The yield, particle size, and zeta potential of the doxorubicin-loaded nanoparticles were measured. The amount of doxorubicin loaded into the nanoparticles in terms of drug loading (equation [4]) and encapsulation efficiency (equation [5]) were determined by dissolving $0.5 \mathrm{mg}$ nanoparticles in $1 \mathrm{~mL}$ of acetone and measurement by fluorescence spectrophotometer (F-4500, Hitachi, Tokyo, Japan) at an excitation wavelength of $503 \mathrm{~nm}$ and an emission wavelength of $550 \mathrm{~nm} .^{44}$

Drug loading (\%)

$=\frac{\text { Determined amount of doxorubicin in nanoparticles }}{\text { Weight of nanoparticle }} \times 100 \%$ 
Encapsulation efficiency (\%)

$=\frac{\text { Determined amount of doxorubicin in NPs }}{\text { Initially added amount of doxorubicin } * \text { Yield }} \times 100 \%$

\section{In vitro release study}

Doxorubicin-loaded peptide-free and peptide-conjugated PLGA-PEG nanoparticles (5 mg) were resuspended in $1 \mathrm{~mL}$ of phosphate-buffered saline $(\mathrm{pH} 7.4,0.01 \%$ sodium azide, $0.5 \%$ Tween 80 ) or $1 \mathrm{~mL}$ of acetic-buffered solution ( $\mathrm{pH} 4.0,500 \mathrm{U}$ lipase, $0.01 \%$ sodium azide, $0.5 \%$ Tween 80 ) and then added into the dialysis bag (molecular weight cutoff $6000-8000 \mathrm{Da}$ ). The dialysis bag was placed in a $200 \mathrm{~mL}$ bottle containing $100 \mathrm{~mL}$ phosphate-buffered or acetic-buffered solution and stirred at $100 \mathrm{rpm}$ and $37^{\circ} \mathrm{C}$. Next, $1 \mathrm{~mL}$ of medium was withdrawn at each specific time interval and the same volume of fresh release medium was replaced. The fluorescence intensity of the doxorubicin released was measured at an excitation wavelength of $496 \mathrm{~nm}$ and an emission wavelength of $556 \mathrm{~nm}$.

\section{Cytotoxicity study}

SKOV3 cells were seeded into a 96-well plate at a density of 9000 cells per well for 24 hours. Serial dilutions of doxorubicin-loaded peptide-free and peptide-conjugated PLGA-PEG nanoparticles in $200 \mu \mathrm{L}$ of McCoy5A medium were added into each well and incubated at $37^{\circ} \mathrm{C}$ for 72 hours in a humidified incubator containing $5 \% \mathrm{CO}_{2}$. The medium was removed and the cells were washed three times with phosphate-buffered saline. The cells were labeled with MTT solution $(0.5 \mathrm{mg} / \mathrm{mL})$ at $37^{\circ} \mathrm{C}$ for 4 hours in a humidified incubator containing $5 \% \mathrm{CO}_{2}$. The resulting formazan was solubilized in $200 \mu \mathrm{L}$ of dimethyl sulfoxide and the absorbance was measured using an enzyme-linked immunosorbent assay reader (Power Wave $\mathrm{XS}$ ) at $570 \mathrm{~nm}$. The $\mathrm{IC}_{50}$ was calculated from the plot of cell viability versus doxorubicin concentration using SigmaPlot 10.0 software. $^{43}$

\section{Biodistribution of doxorubicin in SKOV3 tumor-bearing mice}

Athymic mice (nude, female, 7-8 weeks old, 20-23 g) were maintained in an aseptic environment. The tumors were implanted by injecting $5 \times 10^{6}$ SKOV 3 cells (in $50 \mu \mathrm{L}$ McCoy5A medium and $50 \mu \mathrm{L}$ Matrigel) into the subcutaneous region of each mouse. At predetermined time points, the major and minor axes of the tumors were measured using a caliper. The tumor volume was calculated using the formula $a^{2} b / 2$, where $a$ and $b$ are the lengths of the minor and major axes of the tumor, respectively. ${ }^{45,46}$ All animals were accommodated in a pathogen-free laboratory environment throughout the experiments. After implantation, the tumors were allowed to grow for 21 days, and the mean tumor volume was about $100 \mathrm{~mm}^{3}$. The animals received a single intravenous injection of free doxorubicin, doxorubicin-loaded peptidefree, or peptide-conjugated PLGA-PEG nanoparticles at an equivalent doxorubicin dose of $5 \mathrm{mg} / \mathrm{kg}$. After 24 hours, blood samples were collected, the animals were sacrificed, and the brains, hearts, livers, kidneys, and tumor tissue were removed without perfusion. The organs were freeze-dried and weighed. Lyophilized tissue was homogenized in sodium phosphate buffer ( $\mathrm{pH} 7.4$ ) in an ice bath, and then extracted using a mixture of chloroform and isopropanol (3:1, v/v). The organic layer was collected after centrifugation, then completely dried under vacuum and redissolved in acetone. The solution was determined with a fluorescence detector at an excitation wavelength of $503 \mathrm{~nm}$ and an emission wavelength of $546 \mathrm{~nm}$.

\section{Results and discussion Characterization of PLGA-PEG copolymer}

Figure 1 shows the ${ }^{1} \mathrm{H}-\mathrm{NMR}$ spectra for PLGA-PEG synthesized at a molar feed ratio of PLGA-NHS:PEG diamine 1:1. Four peaks were present, including peak $a$ at $\delta 5.30-5.17 \mathrm{ppm}$ for the $\mathrm{CH}$ proton of lactide, peak $b$ at $\delta 4.90-4.56 \mathrm{ppm}$ for the $\mathrm{CH}_{2}$ proton of glycolide, peak $c$ at $\delta 3.61-3.55 \mathrm{ppm}$ for the $\mathrm{CH}_{2}$ proton of ethylene glycol, and peak $d$ at $\delta$ 1.62-1.45 ppm for the $\mathrm{CH}_{3}$ proton of lactide. There was a small peak at $\delta 6.10-6.20 \mathrm{ppm}$, indicating the presence of an amide bond between PLGA and PEG (Figure 1A inset). ${ }^{47}$ All of these lines of evidence confirmed the presence of both PLGA and PEG domains in the PLGA-PEG copolymer. The synthesis yield of PLGA-PEG was $94.1 \%$, and the PEGylation efficiency was $97.0 \%$ in terms of $10.3 \% \mathrm{w} / \mathrm{w}$ PEG in the synthesized PLGA-PEG copolymer. The weight-average molecular weight $\left(\mathrm{M}_{\mathrm{w}}\right)$, number-average molecular weight $\left(\mathrm{M}_{\mathrm{n}}\right)$, and polydispersity of PLGA-PEG were $32.6 \mathrm{kDa}$, $17.6 \mathrm{kDa}$, and 1.8 , respectively. The critical micelle concentration of the amphiphilic PLGA-PEG copolymer was determined using pyrene as a fluorescence probe. There were no micelles formed at a concentration below the critical micelle concentration. Above the critical micelle concentration, the fluorescence intensity abruptly increased and the slope markedly increased. The critical micelle concentration for PLGA-PEG was determined to be $3.0 \times 10^{-8} \mathrm{~mol} / \mathrm{L}$. 


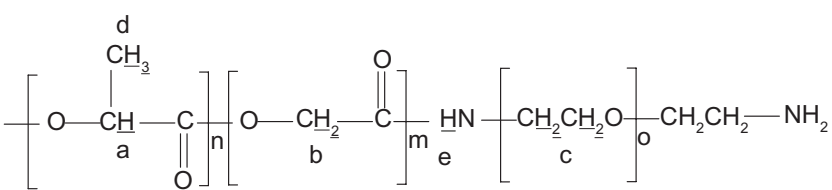

A

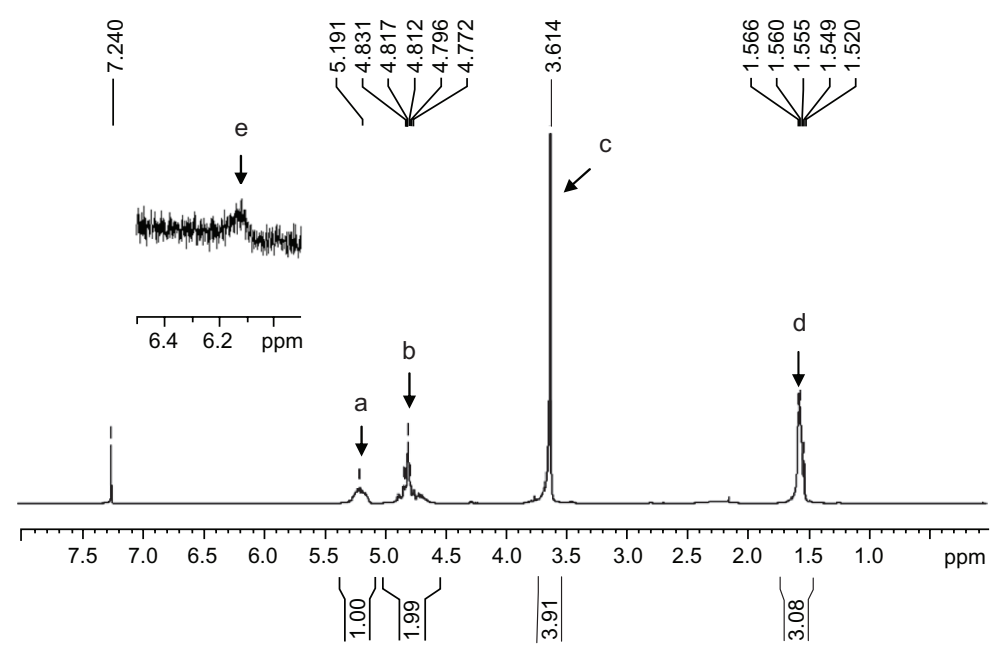

B

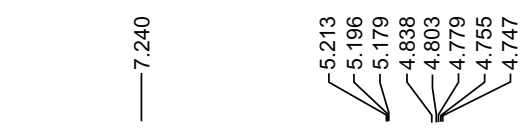

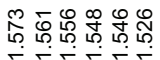
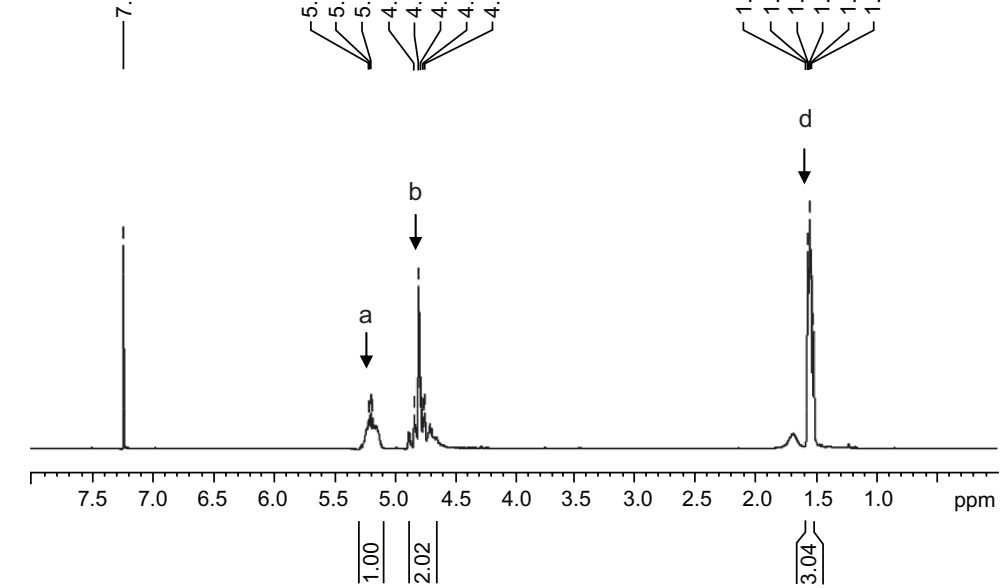

C

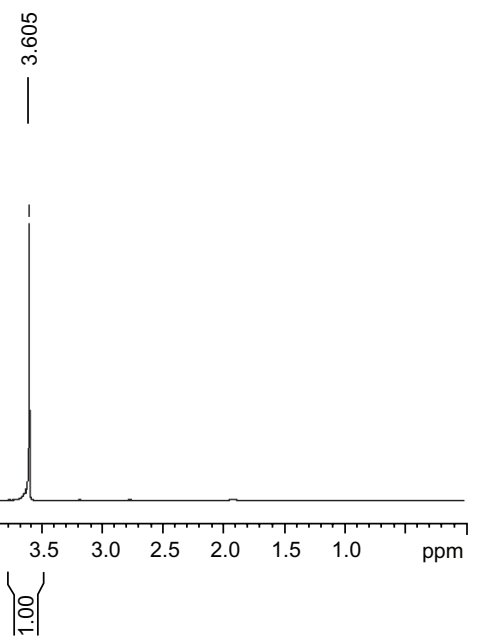

Figure I 'H-NMR spectra of (A) PLGA-PEG, (B) PLGA, and (C) PEG diamine. Abbreviations: PEG, poly(ethylene glycol); PLGA, poly(D,L-lactide-co-glycolide). 
Lee et al demonstrated that PLA-PEG micelles with a critical micelle concentration of $8.1 \times 10^{-7} \mathrm{~mol} / \mathrm{L}$ had good stability in the bloodstream. ${ }^{48}$ The critical micelle concentration for our synthesized PLGA-PEG copolymer $\left(3.0 \times 10^{-8} \mathrm{~mol} / \mathrm{L}\right)$ was lower than that of the reported value $\left(8.1 \times 10^{-7} \mathrm{~mol} / \mathrm{L}\right)$. Our PLGA-PEG micelles had the potential to maintain their stable core-shell conformation in the circulation.

\section{Characterization of PLGA-PEG nanoparticles}

PLGA-PEG nanoparticles were prepared using the solvent evaporation method. The average size of the PLGA and PLGA-PEG nanoparticles was $105.3 \pm 2.61 \mathrm{~nm}$ and $134.6 \pm 5.57 \mathrm{~nm}$, and the polydispersities were $0.023 \pm 0.017$ and $0.103 \pm 0.085$, indicating a narrow size distribution. The zeta potential of the PLGA and PLGA-PEG nanoparticles was $-4.4 \pm 0.85 \mathrm{mV}$ and $-13.3 \pm 0.80 \mathrm{mV}$, respectively. Both nanoparticles were negatively charged, and thus able to avoid nonspecific interaction with the cell membrane by electrostatic interaction. Figure 2 shows the morphology of PLGA and PLGA-PEG nanoparticles observed by transmission electron microscopy. All of the nanoparticles had a spherical shape and uniform size without aggregation. The PLGA nanoparticles showed a clear and sharp margin around the surface (Figure 2A inset). However, the PLGA-PEG nanoparticles showed a rigid PLGA core with a fuzzy appearance around the surface (Figure 2B inset). The shielding effect of the PEG polymer chains around the PLGA-PEG nanoparticle surface accounted for this appearance. Covering of nanoparticle surfaces with hydrophilic PEG has been shown to prolong the circulation time of nanoparticles in vivo. The hydrophilic PEG polymer chains sterically stabilize nanoparticles against opsonization and subsequent phagocytosis. Kim et al reported that nanoparticles with a particle size less than $200 \mathrm{~nm}$ are preferred in a long circulating drug delivery system because they can evade uptake by the reticuloendothelial system in the spleen. ${ }^{49}$ Ioele et al demonstrated that extension of PEG polymer chains on the nanoparticle surface acts as a steric barrier to reduce clearance of the nanoparticles by macrophages in the liver and promote the enhanced permeation and retention effect. ${ }^{50}$ van Vlerken et al also found that PLGA nanoparticles surface-modified with PEG avoid uptake by the reticuloendothelial system, thereby improving the nanoparticle circulation time, and the nanoparticles are retained in the tumor tissue for prolonged periods of time..$^{51}$ All of these observations supported our PEGylated PLGA nanoparticles, with a size less than $200 \mathrm{~nm}$, having potential as a nanocarrier with long-circulating properties.
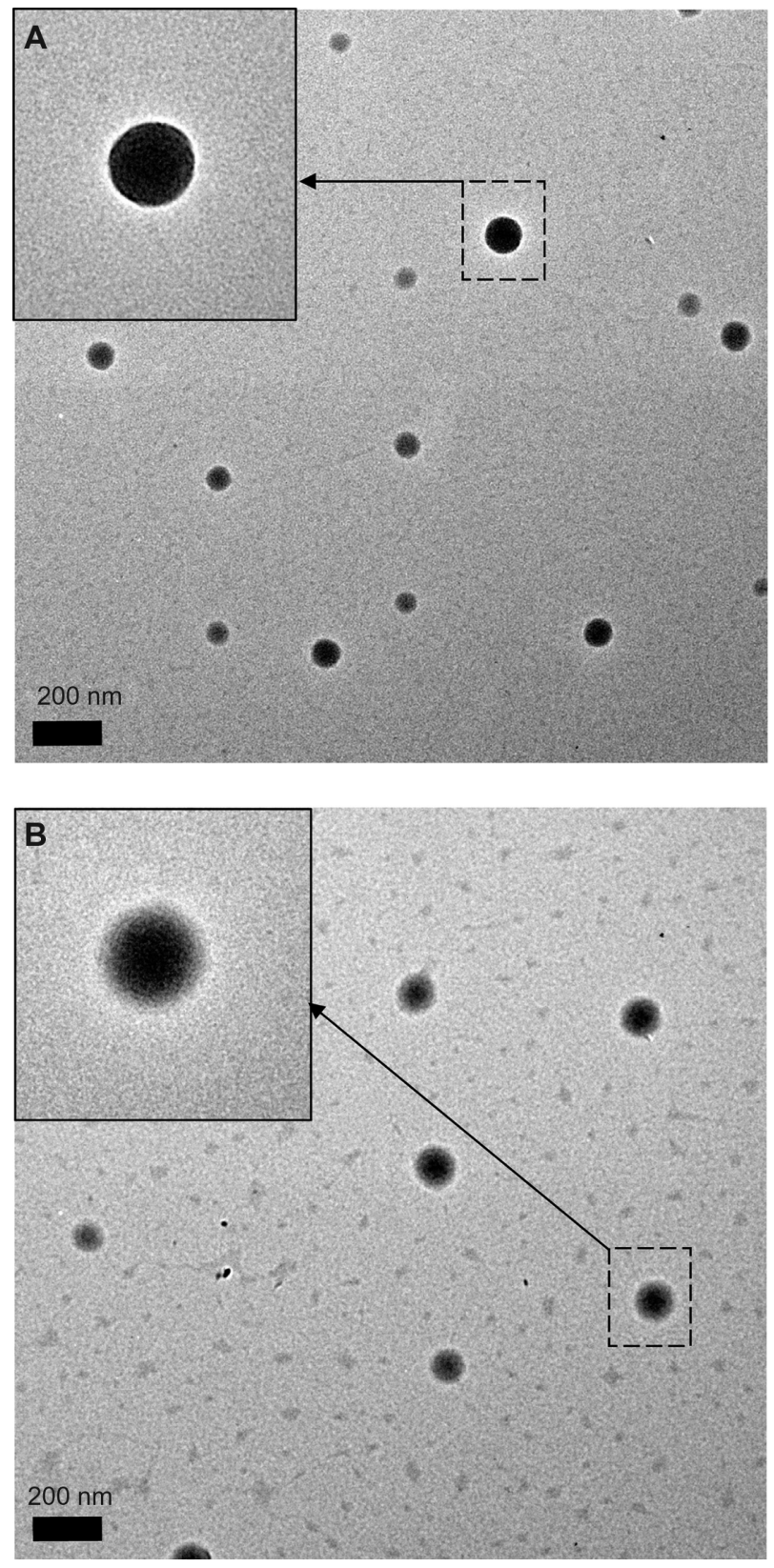

Figure 2 Transmission electron microscopic images of (A) PLGA nanoparticles and (B) PLGA-PEG nanoparticles with magnification 9600x.

Note: The insets indicated by arrows have a magnification 19,000x.

Abbreviations: PEG, poly(ethylene glycol); PLGA, poly(D,L-lactide-co-glycolide).

\section{Cytotoxicity of PLGA-PEG nanoparticles}

The cytotoxicity of the PLGA-PEG nanoparticles was evaluated using a L929 cell line of mouse connective tissue fibroblasts, as recommended by the American Society for Testing and Materials (ASTM F895, 2003). ${ }^{52}$ Figure 3 depicts cell viability with PLGA and the PLGA-PEG nanoparticles. The corresponding values at nanoparticle concentrations lower than $0.41 \mathrm{mg} / \mathrm{mL}$ were similar for these two types of nanoparticles and more than $75 \%$ of the cells were viable. 


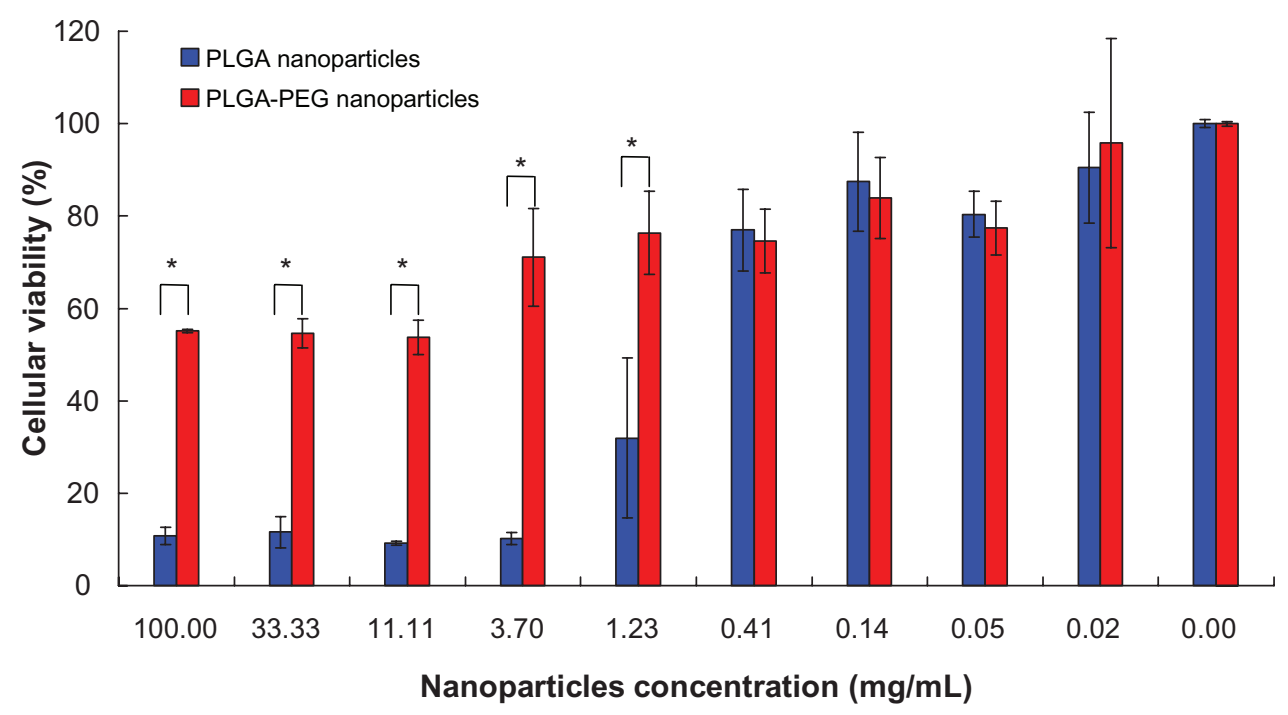

Figure 3 L929 cellular viability of ( $\square)$ PLGA and ( $\square$ ) PLGA-PEG nanoparticles $(n=3)$.

Notes: Percentage viability of $L 929$ cell line was analyzed by MTT assay. The values are represented as the mean \pm standard deviation, $n=3$. Error bars indicate the standard deviation. $* P<0.05$ by Student's $t$-test.

Abbreviations: PEG, poly(ethylene glycol); PLGA, poly(D,L-lactide-co-glycolide).

However, cell viability was markedly decreased by PLGA nanoparticle concentrations higher than $1.23 \mathrm{mg} / \mathrm{mL}$. Nevertheless, this did not occur for PLGA-PEG nanoparticles, even at a high concentration of $100 \mathrm{mg} / \mathrm{mL}$, and $55.2 \% \pm 0.4 \%$ of the cells were still viable. The calculated $\mathrm{IC}_{50}$ of the PLGA and PLGA-PEG nanoparticles was $1.02 \pm 0.37 \mathrm{mg} / \mathrm{mL}$ and $>100 \mathrm{mg} / \mathrm{mL}$, respectively. In other words, cell viability with PLGA-PEG nanoparticles was improved by more than 98-fold after PEGylation of $10.3 \% \mathrm{w} / \mathrm{w}$. The shielding effect of PEG resulted in nanoparticles with better cell viability. The significantly higher $\mathrm{IC}_{50}$ of PLGA-PEG nanoparticles compared with PLGA nanoparticles indicated that the cytotoxicity of the nanoparticles was reduced and their biocompatibility was improved.

\section{Fluorescein conjugation of PLGA- PEG-FITC and PLGA-PEG NP-FITC}

FITC-conjugated PLGA-PEG was prepared by two different methods. The first method involved conjugation of FITC with PLGA-PEG copolymer following nanoparticle preparation (Scheme 2A). The second method involved conjugation of FITC with previously prepared PLGA-PEG nanoparticles (Scheme 2B). With the first method, as the molar feed ratio of PLGA-PEG:FITC increased from 1:1 to 1:20 after reaction for 2 hours, FITC conjugation ratio of PLGA-PEG-FITC increased from $0.6 \pm 0.3 \mathrm{~mol} \%$ to $28.8 \pm 4.9 \mathrm{~mol} \%$, but the yield decreased from $71.8 \% \pm 2.1 \%$ to $42.5 \% \pm 1.3 \%$. This result shows that the FITC conjugation ratio was significantly improved by increasing the molar feed ratio of FITC. With the second method, the much higher FITC conjugation ratio and yield of PLGA-PEG NP=FITC were achieved as the molar feed ratio of PLGA-PEG NP: FITC 1:1 reaction for 2 hours, where the corresponding values were $96.5 \pm 1.5 \mathrm{~mol} \%$ and $88.5 \% \pm 1.8 \%$. The reaction time was further investigated at 2-24 hours and a molar feed ratio of PLGA-PEG:FITC 1:20 and PLGA-PEG NP:FITC 1:1, and the result is shown in Figure 4. The yields of PLGA-PEG-FITC copolymer were between $45.41 \% \pm 2.57 \%$ and $50.28 \% \pm 0.70 \%$ which increased slightly as the reaction time was increased from 2 to 24 hours (Figure 4A). In contrast, the FITC conjugation ratio was markedly increased from $28.80 \pm 4.94 \mathrm{~mol} \%$ to $81.13 \pm 6.84 \mathrm{~mol} \%$ as the reaction time increased from 2 to 4 hours. A further increase in reaction time to 6 hours and 24 hours only increased the conjugation ratios slightly to $91.37 \pm 2.43 \mathrm{~mol} \%$ and $94.87 \pm 6.89 \mathrm{~mol} \%$, respectively. This result indicates that the 6-hour reaction period was long enough to achieve $90 \mathrm{~mol} \%$ conjugation of FITC with PLGAPEG-FITC. The effect of reaction time (2-24 hours) on the FITC conjugation molar ratio and yield of PLGA-PEG NPFITC was investigated at a PLGA-PEG nanoparticle molar feed ratio of FITC 1:1, and the result is shown in Figure 4B. There was no prominent change in yield of PLGA-PEG NPFITC within 24 hours of reaction time, and the corresponding values were in the range of $86.9 \% \pm 4.0 \%$ and $90.6 \% \pm 2.4 \%$. However, the FITC conjugation ratio was markedly decreased from $96.5 \pm 1.5 \mathrm{~mol} \%$ to $41.9 \pm 2.5 \mathrm{~mol} \%$ when the reaction 
A

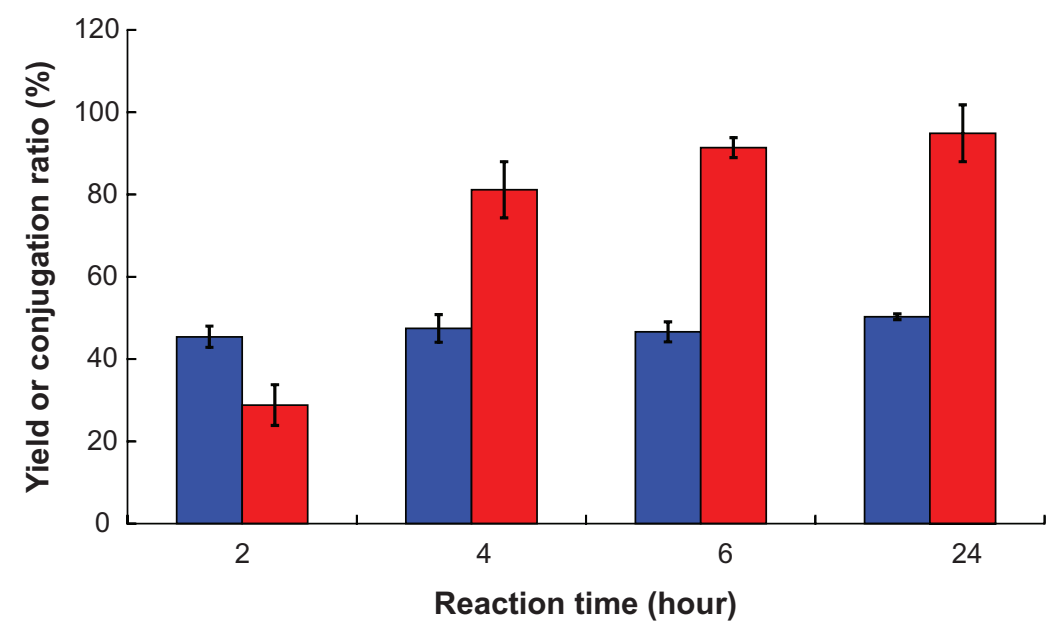

B

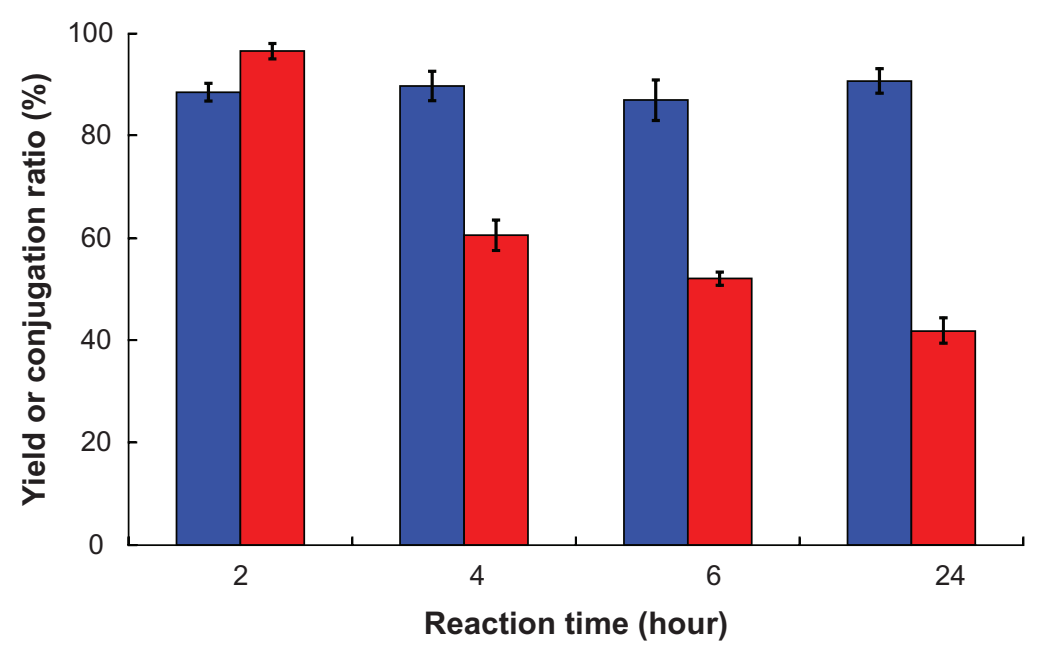

Figure 4 Effect of reaction time on ( $\square)$ yield and ( $\square)$ FITC conjugation ratio of (A) PLGA-PEG-FITC reacted at a molar feed ratio of PLGA-PEG:FITC I:20, and (B) PLGAPEG NP-FITC reacted at a molar feed ratio of PLGA-PEG NP:FITC I:I.

Abbreviations: PLGA, poly(D,L-lactide-co-glycolide); PEG, poly(ethylene glycol); FITC, fluorescein isothiocyanate; NP, nanoparticle.

time was increased from 2 to 24 hours. All of these results indicate that conjugation of FITC with PLGA-PEG was preferred after formation of the micellar core-shell conformation. The amphiphilic properties of PLGA-PEG formed a core-shell conformation in the aqueous environment during the conjugation process, whereby the hydrophilic PEG chains extended outside of PLGA-PEG nanoparticles. This special feature enabled the amino group at the end of the PEG chain surrounding the surface of the PLGA-PEG nanoparticles to react efficiently with FITC. This resulted in a FITC conjugation ratio of PLGA-PEG NP-FITC that was higher than PLGA-PEG-FITC.

\section{Characterization of PLGA-PEG NP-FITC and PLGA-PEG NP-peptide-FITC}

A peptide which mimicked the EGF receptor was used in this study as a ligand. The terminal amino group of PLGAPEG was further conjugated with the carboxyl group of peptide-FITC as depicted in Scheme 2B(II), whereby the molar feed ratio of PLGA-PEG NP-peptide-FITC was 1:1 and the reaction time was 2 hours. The conjugation ratio and yield of the resulting PLGA-PEG NP-peptide-FITC were $71.1 \pm 4.8 \mathrm{~mol} \%$ and $89.6 \pm 6.3 \%$, respectively. The larger molecular weight of peptide-FITC (molecular weight 1276.49) than of FITC (molecular weight 389.4) might be 
an obstacle resulting conjugation ratio of PLGA-PEG NPpeptide-FITC (71.1 $\pm 4.8 \mathrm{~mol} \%)$ lower than PLGA-PEG NP-FITC $(96.5 \pm 1.5 \mathrm{~mol} \%)$. The particle size of the peptide-free and peptide-conjugated PLGA-PEG nanoparticles was $178.9 \pm 4.47 \mathrm{~nm}$ and $179.7 \pm 2.39 \mathrm{~nm}$, respectively, with a polydispersity of $0.103 \pm 0.087$ and $0.111 \pm 0.044$, indicating a narrow distribution, and the corresponding zeta potential was $-26.60 \pm 5.06 \mathrm{mV}$ and $-16.70 \pm 3.04 \mathrm{mV}$. All nanoparticles maintained a negatively charged surface, and the peptide-conjugated PLGA-PEG nanoparticles were less negative than for peptide-free PLGA-PEG nanoparticles due to the presence of two positively charged arginine amino acids in the conjugated peptide. Figure 5 shows the ${ }^{1} \mathrm{H}-\mathrm{NMR}$ spectra for the peptide-conjugated and peptide-free PLGA-PEG nanoparticles (400 $\mathrm{mHz}, \mathrm{CDCl}_{3}$ ). Singh et al reported that the NMR chemical shifts in peptides represent a population-weighted average of rapidly interconverting peptide structures, and the chemical shifts of asparagine and arginine were reported to be $2.7 \mathrm{ppm}$ and $2.9 \mathrm{ppm}$, respectively. ${ }^{53}$ There is a new peak at 2.6 ppm in Figure $5 \mathrm{~A}$ of peptide-conjugated PLGA-PEG nanoparticles. Asparagine and arginine are two amino acids partially comprising the
NR7 peptide. The presence of a 2.6 ppm peak confirmed that the NR7 peptide was successfully conjugated with the PLGA-PEG nanoparticles.

\section{Cell uptake}

SKOV3 is a cell line with high expression of the EGF receptor and has been used to demonstrate the cellular uptake of peptide-free and peptide-conjugated PLGA-PEG nanoparticles. The result is shown in Figure 6. Cellular uptake of the nanoparticles increased with increasing nanoparticle concentration, and more enhancement was observed for peptide-conjugated nanoparticles than for peptide-free nanoparticles. After incubation with a given $22.2 \mu \mathrm{M}$ fluorescein concentration of peptide-conjugated nanoparticles with SKOV3 cells for 30 minutes, cellular uptake was observed to be $37.9 \%$, but was only $11.3 \%$ after incubation with a given $25.3 \mu \mathrm{M}$ fluorescein concentration of peptide-free nanoparticles. The presence of the peptide enhanced nanoparticle uptake by more than three-fold in SKOV3 cells with high expression of the EGF receptor. The peptide on the surface of the PLGA-PEG nanoparticles enabled binding to the EGF receptor and was further
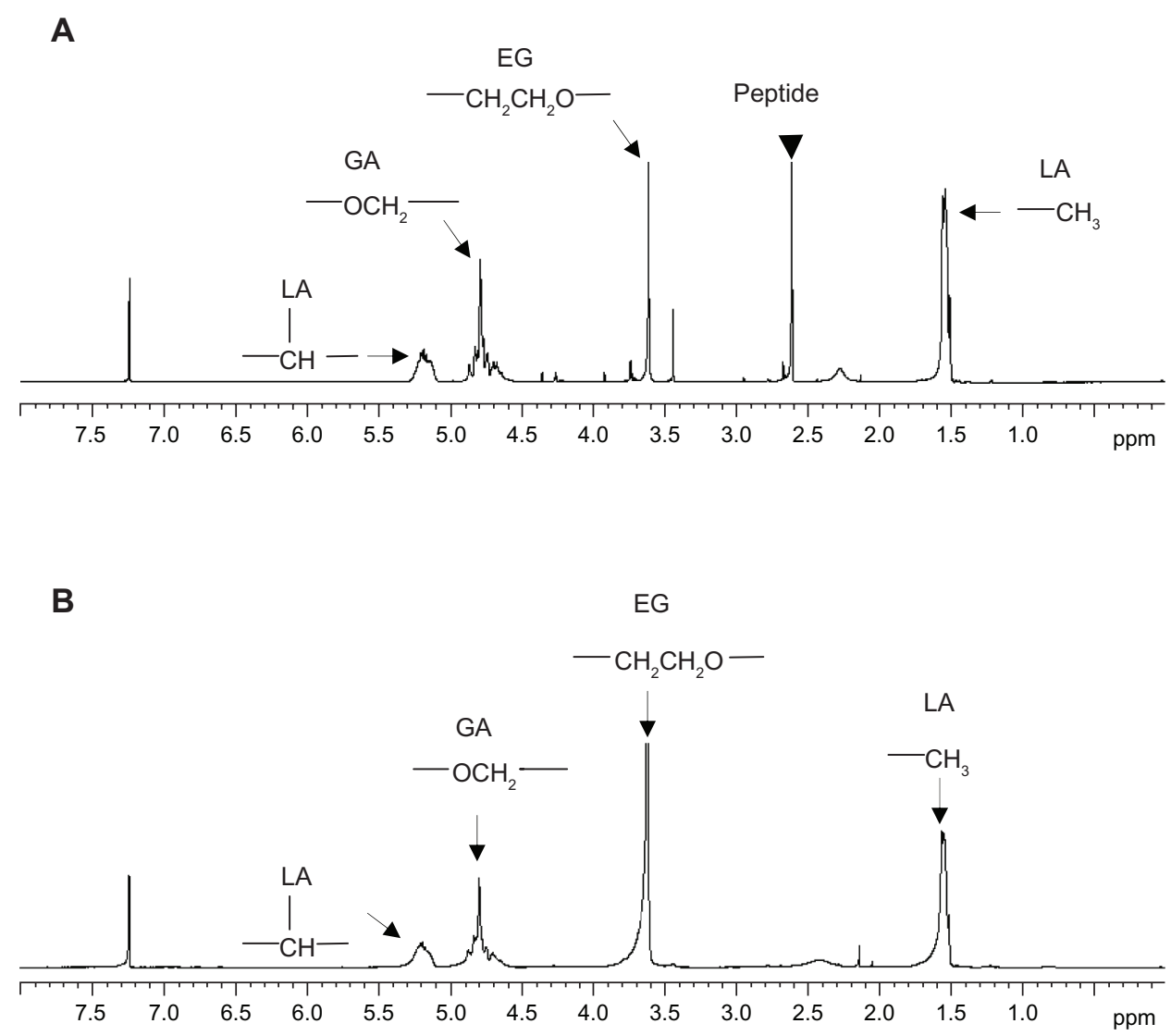

Figure 5 'H-NMR spectra of (A) peptide-conjugated and (B) peptide-free PLGA-PEG nanoparticles $\left(400 \mathrm{mHz}, \mathrm{CDCl}_{3}\right)$. Abbreviations: PLGA, poly(D,L-lactide-co-glycolide); PEG, poly(ethylene glycol). 


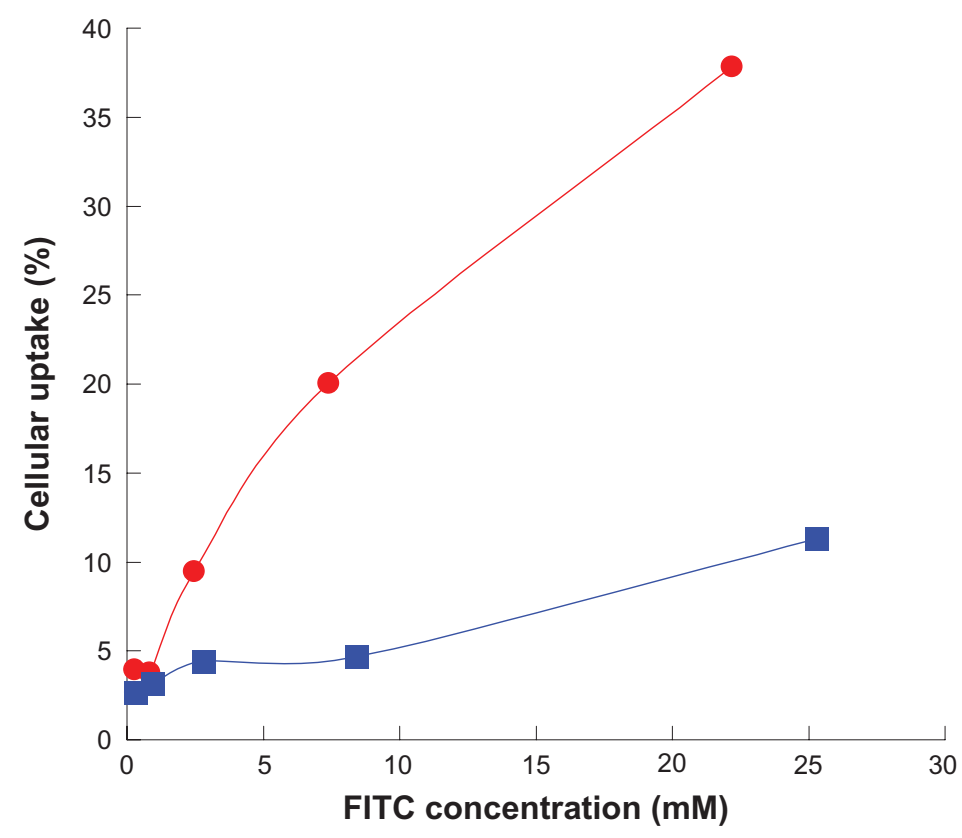

Figure 6 Cellular uptake of $(\square)$ peptide-conjugated and $(\bullet)$ peptide-free PLGA-PEG nanoparticles in a SKOV3 cell line with high expression of the epithelial growth factor receptor at $37^{\circ} \mathrm{C}$ for 30 minutes.

Abbreviations: FITC, fluorescein isothiocyanate; PLGA, poly(D,L-lactide-co-glycolide); PEG, poly(ethylene glycol).

internalized into SKOV3 cells. ${ }^{54}$ All of these results suggest that the terminal amino group of the amphiphilic PLGAPEG copolymer was successfully conjugated with the NR7 peptide, and the resulting peptide-conjugated nanoparticles possessed active targeting ability to SKOV3 cells with high expression of the EGF receptor.

\section{Characterization of doxorubicin-loaded nanoparticles}

Doxorubicin is one of the most potent and widely used anticancer drugs. Its anticancer activity results from inhibition of nucleic acid synthesis in cancer cells. ${ }^{55}$ Doxorubicinloaded nanoparticles were prepared and characterized. The yields of doxorubicin-loaded peptide-free and peptideconjugated PLGA-PEG nanoparticles were 76.5\% $\pm 3.4 \%$ and $81.0 \% \pm 0.8 \%$ and the corresponding particle size was $185.7 \pm 16.7 \mathrm{~nm}$ and $178.5 \pm 16.2 \mathrm{~nm}$. The polydispersity index was $0.111 \pm 0.044$ and $0.029 \pm 0.005$, respectively, and the zeta potential was $-15.0 \pm 4.3 \mathrm{mV}$ and $0.60 \pm 5.04 \mathrm{mV}$. The particle size of both kinds of doxorubicin-loaded nanoparticles was less than $200 \mathrm{~nm}$, with a narrow distribution, and the zeta potential of the peptide-conjugated nanoparticles was less negative than that of the peptide-free nanoparticles due to conjugation with positively charged peptides. The doxorubicin loading of the peptide-free and peptideconjugated PLGA-PEG nanoparticles was $4.1 \% \pm 1.4 \%$ and $4.8 \% \pm 0.7 \%$, and the encapsulation efficiency was
$99.9 \% \pm 5.8 \%$ and $97.7 \% \pm 4.1 \%$. The encapsulation of doxorubicin in the two types of nanoparticles was similar, regardless of the presence of the peptide.

\section{In vitro release of doxorubicin-loaded nanoparticles}

Figure 7 shows the release of doxorubicin from peptide-free and peptide-conjugated PLGA-PEG nanoparticles at physiological $\mathrm{pH}$ (7.4) and simulated lysosomal $\mathrm{pH}$ (4.0, $500 \mathrm{U}$ lipase) release media. The initial release of doxorubicin from peptide-free and peptide-conjugated nanoparticles was $21.0 \% \pm 2.1 \%$ and $33.9 \% \pm 0.6 \%$ at $\mathrm{pH} 7.4$ in the first 6 hours. The surface to volume ratio of the nanoparticles was large, resulting in rapid drug release at or near the particle surface. ${ }^{44}$ There was $65.6 \% \pm 4.9 \%$ and $99.2 \% \pm 4.8 \%$ drug release from the peptide-conjugated nanoparticles in $\mathrm{pH} 7.4$ and $\mathrm{pH} 4.0$ (500 U lipase) during the first 24 hours, and the corresponding value released from the peptide-free nanoparticles was $39.1 \% \pm 3.7 \%$ and $97.9 \% \pm 3.4 \%$. The doxorubicin release pattern was similar for both kinds of PLGA-PEG nanoparticles, whereby the drug was completely released at pH 4.0 (500 U lipase) within 24 hours, but release of doxorubicin was sustained for 5-6 days at $\mathrm{pH}$ 7.4. The release of doxorubicin from the peptide-conjugated nanoparticles was faster than from the peptide-free nanoparticles at $\mathrm{pH}$ 7.4. Khoee et al demonstrated that faster drug release from folate nanoparticles was due to the hydrophilicity of folate which 


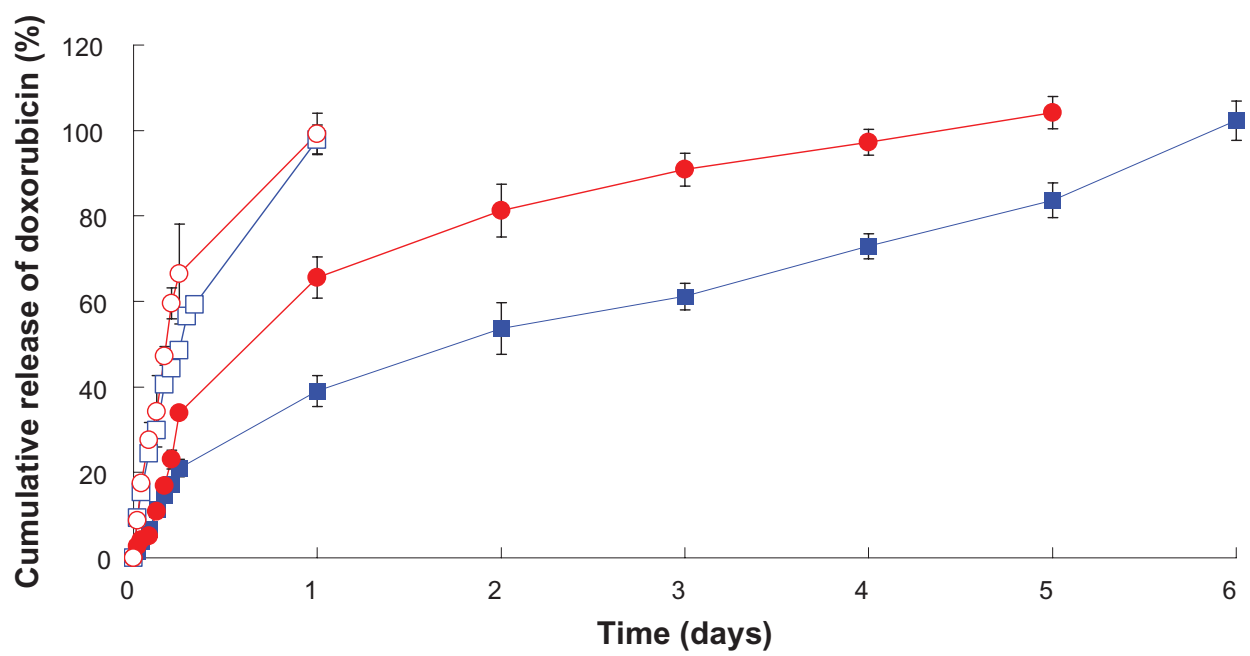

Figure 7 In vitro release of doxorubicin from peptide-free and peptide-conjugated PLGA-PEG nanoparticles in pH 4.0 (500 U lipase) and pH 7.4 release media. ( $($ ) Peptideconjugated nanoparticles, pH 4.0 (500 U lipase). ( $\square$ ) Peptide-free nanoparticles, pH 4.0 (500 U lipase). (•) Peptide-conjugated nanoparticles, pH 7.4. ( $\square$ ) Peptide-free nanoparticles, $\mathrm{pH}$ 7.4.

Abbreviations: PLGA, poly(D,L-lactide-co-glycolide); PEG, poly(ethylene glycol).

facilitated uptake of water from nanoparticles and caused faster drug release. ${ }^{56}$ The NR7 peptide was hydrophilic, which might enhance uptake of water by nanoparticles and accelerate hydrolysis of the PLGA-PEG copolymer. All of these factors resulted in faster doxorubicin release from the peptide-conjugated nanoparticles. The release of doxorubicin from peptide-free and peptide-conjugated PLGA-PEG nanoparticles in $\mathrm{pH} 4.0$ medium containing lipase was significantly faster than in $\mathrm{pH} 7.4$ medium. Gillies et al demonstrated that the increase in aqueous solubility of doxorubicin and enhancing hydrolysis of the polymer in a mildly acidic medium (pH 5.0) resulted in faster release of doxorubicin. ${ }^{57}$ Unger et al indicated that PLGA was degraded by hydrolysis and that acidic conditions further catalyzed the hydrolysis process. ${ }^{58}$ Our results indicate that the release of doxorubicin was faster in $\mathrm{pH} 4.0$ medium containing lipase than in $\mathrm{pH} 7.4$ medium. The faster hydrolysis of the PLGA-PEG copolymer in acid buffer than in phosphate-buffered saline partially accounts for this result. In addition, the PLGA-PEG copolymer can be degraded by lipase, a type of esterase, to enhance doxorubicin release in a simulated lysosomal environment ( $\mathrm{pH} 4.0$ with lipase)..$^{59}$ The $\mathrm{pH}$ values of the intracellular compartments, including the endosomes and lysosomes, were reported to be in the range of 4.5-6.5. The average extracellular $\mathrm{pH}$ value of cancerous tissue is 6.8 , which is caused by hypoxia that upregulates glycolysis following by production of lactate and protons in the extracellular microenvironment. ${ }^{60}$ Compared with normal tissue ( $\mathrm{pH} 7.4$ ), the existing $\mathrm{pH}$ of tumor tissue is considered to be an ideal trigger for selective release of doxorubicin from tumor tissues and within tumor cells.
Overall, these results indicate that doxorubicin-loaded peptidefree and peptide-conjugated PLGA-PEG nanoparticles were stable at $\mathrm{pH} 7.4$, whereby doxorubicin was not released from the nanoparticles during circulation in the blood and the undesirable toxicity of free doxorubicin in normal organs could be avoided. Both the doxorubicin-loaded peptide-free and peptide-conjugated PLGA-PEG nanoparticles accumulated in cancerous tissue via the enhanced permeation and retention effect. Most peptide-conjugated nanoparticles were taken up by the cancer cells through receptor-mediated endocytosis, but only a few peptide-free nanoparticles entered the cancer cells. Doxorubicin would be released rapidly from peptideconjugated nanoparticles in the lysosome. Free doxorubicin released from the nanoparticles in the cancer cells entered the nuclei and induced apoptosis of cancer cells without being toxic to normal cells. All of these results indicate that release of doxorubicin from PLGA-PEG nanoparticles was pH-dependent and enzyme-sensitive.

\section{Inhibition of cell growth}

Inhibition of SKOV3 cell growth by doxorubicin-loaded nanoparticles was investigated after 72 hours of incubation, and the result is shown in Figure 8. The $\mathrm{IC}_{50}$ for doxorubicin-loaded peptide-free and for peptide-conjugated PLGA-PEG nanoparticles was $3.12 \pm 1.44 \mu \mathrm{g} / \mathrm{mL}$ and $0.05 \pm 0.03 \mu \mathrm{g} / \mathrm{mL}$, respectively $(P<0.01)$. In other words, the $\mathrm{IC}_{50}$ of doxorubicin-loaded peptide-conjugated nanoparticles in SKOV3 cells was 62.4-fold lower than that of doxorubicin-loaded peptide-free nanoparticles. These results indicate that the cytotoxicity of doxorubicin was significantly 


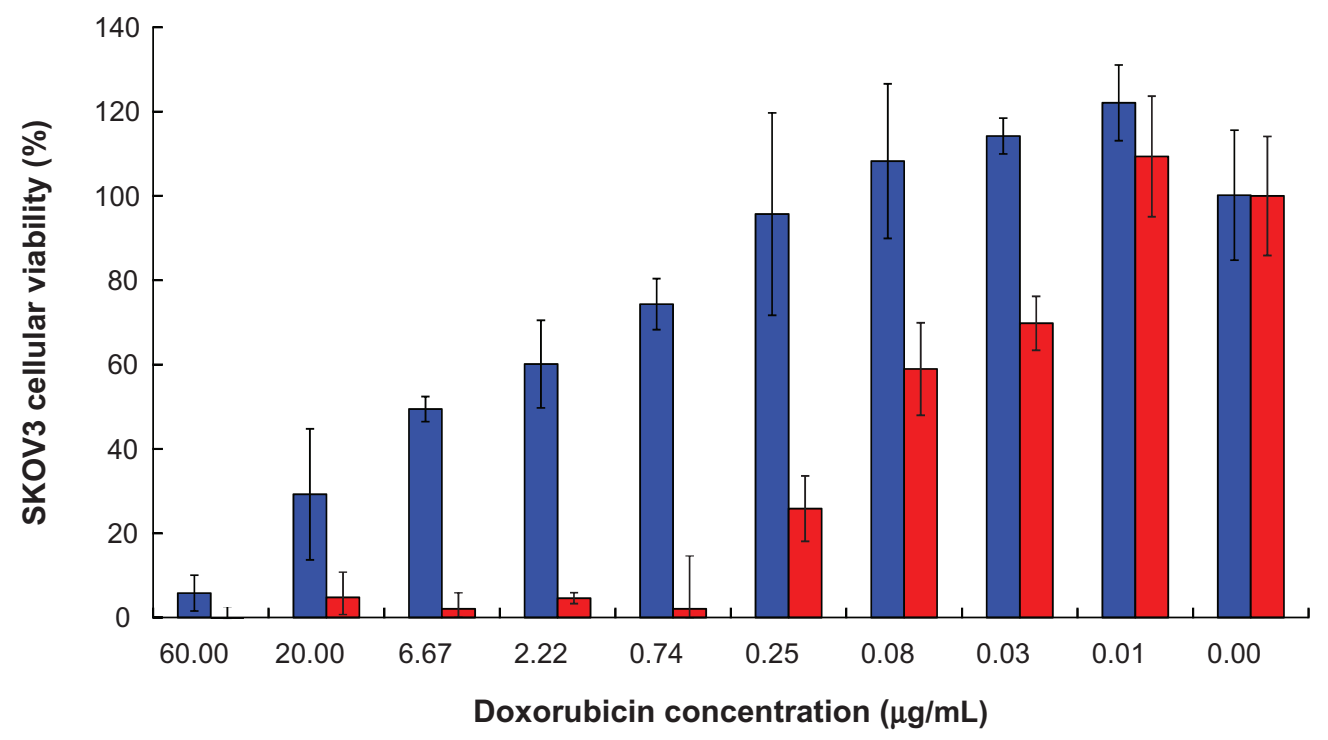

Figure 8 SKOV3 cell growth inhibition by $(\square)$ doxorubicin-loaded peptide-free PLGA-PEG nanoparticles and ( $\square$ ) doxorubicin-loaded peptide-conjugated nanoparticles after 72 hours of incubation.

Abbreviations: PLGA, poly(D,L-lactide-co-glycolide); PEG, poly(ethylene glycol).

enhanced by peptide-conjugated nanoparticles. $\mathrm{The}^{\mathrm{IC}} \mathrm{C}_{50}$ of free doxorubicin has been reported to be $0.18 \pm 0.02 \mu \mathrm{g} / \mathrm{mL}$

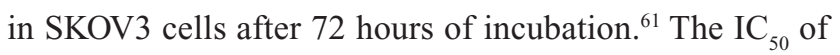
our doxorubicin-loaded peptide-conjugated PLGA-PEG nanoparticles was $0.05 \pm 0.03 \mu \mathrm{g} / \mathrm{mL}$, which was lower than that of free doxorubicin. In other words, inhibition of cell growth by free doxorubicin was also improved by peptide-conjugated PLGA-PEG nanoparticles. Enhancement of PLGA-PEG nanoparticle internalization via conjugation of a peptide that recognizes the EGF receptor results in more drug being transported into SKOV3 cells with high expression of the EGF receptor to achieve better inhibition of cell growth.

\section{Biodistribution of doxorubicin in SKOV3 tumor-bearing mice}

In order to investigate the passive and active targeting effects of doxorubicin-loaded peptide-free and peptide-conjugated PLGA-PEG nanoparticles, the amounts of doxorubicin in the blood, tumor, brain, heart, liver, and kidney tissues of SKOV3 mice with tumor xenografts were determined. Figure 9A shows the plasma doxorubicin concentration 24 hours following administration of free doxorubicin, and peptide-free and peptide-conjugated PLGA-PEG nanoparticles. No doxorubicin was detected with free doxorubicin, which rapidly disappeared from the circulation within 24 hours of systemic administration due to its short half-life. ${ }^{61}$ For peptide-free and peptide-conjugated PLGA-PEG nanoparticles, the plasma doxorubicin levels were $132.06 \pm 49.14 \mathrm{ng} / \mathrm{mL}$ and $286.14 \pm 70.84 \mathrm{ng} / \mathrm{mL}$, respectively. The superiority of doxorubicin-loaded nanoparticles in vivo as compared with free doxorubicin may be attributable to the sustained release and prolonged circulation time of the nanoparticles. In addition, the doxorubicin concentration achieved by peptide-conjugated PLGA-PEG nanoparticles was higher than that achieved by peptide-free PLGA-PEG nanoparticles. Figure 9B shows accumulation of doxorubicin in tumor tissue 24 hours following administration of free doxorubicin, and peptide-free and peptideconjugated PLGA-PEG nanoparticles. For free doxorubicin, the doxorubicin level in the tumor was $0.34 \pm 0.13 \mu \mathrm{g} / \mathrm{g}$. In contrast, when peptide-free or peptide-conjugated PLGAPEG nanoparticles were administered, a higher doxorubicin level was maintained, and the corresponding values were $4.69 \pm 0.90 \mu \mathrm{g} / \mathrm{g}$ and $12.06 \pm 3.65 \mu \mathrm{g} / \mathrm{g}$, respectively. It can be seen that the peptide-free and peptide-conjugated PLGAPEG nanoparticles accumulated at the tumor sites to a greater extent than did free doxorubicin. This can be attributed to the enhanced permeation and retention effect. Moreover, the peptide-conjugated PLGA-PEG nanoparticles were more readily taken up by tumor cells via receptor-mediated endocytosis. The combined effect of active targeting and enhanced cellular uptake of peptide-conjugated PLGA-PEG nanoparticles would be the main reason for the amount of doxorubicin accumulated in the tumor tissue to be 2.6-fold higher than for peptide-free PLGA-PEG nanoparticles. Figure 9C shows accumulation of doxorubicin in the brain, heart, liver, kidney, and tumor tissue. A significantly smaller 
A

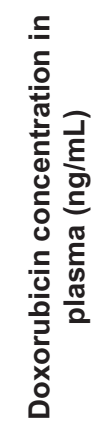

B

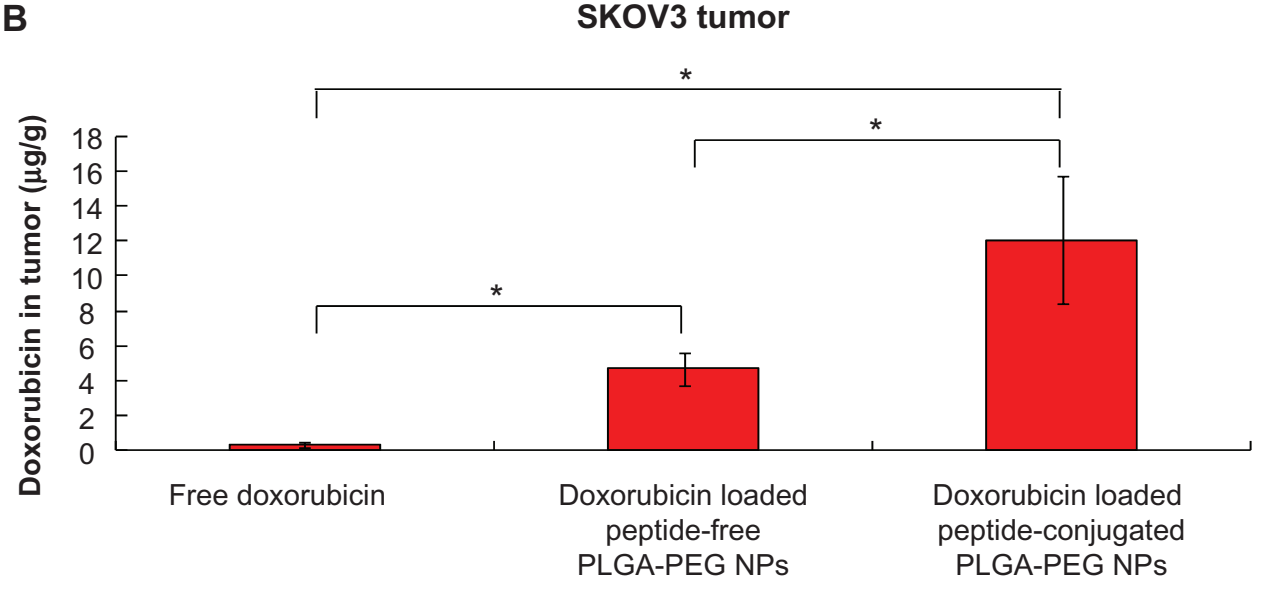

C

Biodistribution study

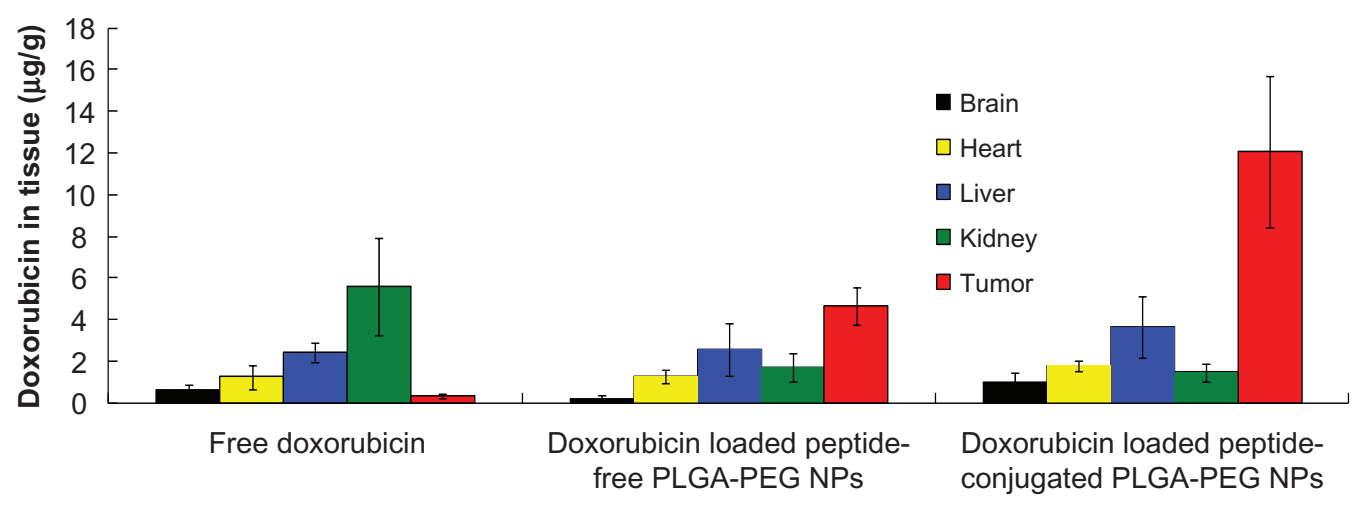

Figure 9 Accumulation and biodistribution of doxorubicin in $(\mathbf{A})$ plasma, $(\mathbf{B})$ tumor, and $(\mathbf{C})$ tissues after intravenous administration of free doxorubicin, and doxorubicinloaded peptide-free and peptide-conjugated PLGA-PEG nanoparticles in SKOV3 tumor-bearing mice at 24 hours.

Abbreviations: PLGA, poly(D,L-lactide-co-glycolide); PEG, poly(ethylene glycol); NPs, nanoparticles.

amount of doxorubicin was detected in the kidney after administration of peptide-free PLGA-PEG nanoparticles $(1.71 \pm 0.66 \mu \mathrm{g} / \mathrm{g})$ and peptide-conjugated PLGA-PEG nanoparticles $(1.46 \pm 0.41 \mu \mathrm{g} / \mathrm{g})$ than with free doxorubicin $(5.59 \pm 2.32 \mu \mathrm{g} / \mathrm{g})$ at 24 hours. The reduced amount of drug accumulation in the kidney could be attributable to selective localization of doxorubicin within the tumor via the enhanced permeation and retention effect. Biodistribution and accumulation of doxorubicin in the brain, heart, liver, and kidney were similar for both kinds of nanoparticles. However, the tumor targeting efficiency was markedly improved by peptide-conjugated PLGA-PEG nanoparticles as compared with peptide-free PLGA-PEG nanoparticles. This result indicates that the peptide acted as an active 
targeting ligand to enhance internalization of nanoparticles into tumor cells via receptor-mediated endocytosis. The doxorubicin accumulation ratio of tumor to liver was in the order of peptide-conjugated PLGA-PEG nanoparticles > peptide-free PLGA-PEG nanoparticles > doxorubicin solution. This result further implies that the lower liver uptake and higher tumor accumulation of doxorubicin was achieved by peptide-conjugated PLGA-PEG nanoparticles due to PEGylation and conjugation of a specific peptide ligand. The doxorubicin-loaded peptide-conjugated nanoparticles led to 30 times more drug being distributed in tumor tissue as compared with intravenous injection of free doxorubicin. This result demonstrates a way to maximize the chemotherapeutic effect of doxorubicin while minimizing its toxic side effects. Considering the results of cellular uptake, and in vitro release and biodistribution studies, doxorubicin was retained in the peptide-conjugated PLGA-PEG nanoparticles in a stable manner, which reduced their nonspecific toxicity to normal tissues during circulation in the blood after intravenous administration. The doxorubicin-loaded peptide-conjugated PLGA-PEG nanoparticles accumulated in tumor tissue via the enhanced permeation and retention effect and receptor-mediated endocytosis. When the peptideconjugated nanoparticles arrived at lysosomes through the endolysosomal pathway, doxorubicin was released rapidly in the lysosomes of SKOV3 cells. The doxorubicin released inside the cancer cells entered the nuclei and induced apoptosis of these cells. Doxorubicin-loaded peptide-conjugated PLGA-PEG nanoparticles acted as an active targeting carrier that increased intracellular accumulation of doxorubicin in SKOV3 cells and reduced side effects in normal tissue.

\section{Conclusion}

In this study, it was demonstrated that the amphiphilic PLGA-PEG copolymer provides an amino end group for peptide conjugation. The PLGA-PEG copolymers synthesized at a 1:1 molar feed ratio for PLGA-NHS:PEG diamine had a PEGylation efficiency of $97.0 \%$ and a low critical micelle concentration of $3.0 \times 10^{-8} \mathrm{~mol} / \mathrm{L}$. The cytotoxicity of PLGA was markedly reduced by more than 98 -fold after PEGylation. The FITC conjugation ratio of PLGA-PEG NP-FITC was significantly higher than of PLGA-PEGFITC. The core-shell conformation provided an amino group at the end of the PEG chain surrounding the surface of the PLGA-PEG nanoparticles to react efficiently with FITC, which resulted in a higher FITC conjugation ratio of PLGA-PEG NP-FITC. Further conjugation of PLGAPEG nanoparticles with the peptide recognizing the EGF receptor had a cellular uptake efficiency which was 3.3-fold superior to that of peptide-free PLGA-PEG nanoparticles. The doxorubicin-loaded nanoparticles were smaller than $200 \mathrm{~nm}$ with a narrow size distribution. The less negative zeta potential of peptide-conjugated nanoparticles compared to peptide-free nanoparticles was due to conjugation of the positively charged peptide with the former. In vitro release of doxorubicin from both kinds of nanoparticles was similar, but was $\mathrm{pH}$-dependent and enzyme-sensitive. The $\mathrm{IC}_{50}$ of doxorubicin-loaded peptide-conjugated nanoparticles in SKOV3 cells expressing high levels of the EGF receptor was $0.05 \pm 0.03 \mu \mathrm{g} / \mathrm{mL}$, which was lower than for the doxorubicin-loaded peptide-free nanoparticles $(3.12 \pm 1.44 \mu \mathrm{g} / \mathrm{mL})$. These results confirm that doxorubicin-loaded peptideconjugated PLGA-PEG nanoparticles possessing active targeting ability not only enhance cellular uptake in SKOV3 cells expressing high levels of the EGF receptor but also have better cellular growth inhibition activity. This finding was further demonstrated in an in vivo biodistribution study in SKOV3 tumor-bearing mice, whereby higher tumor accumulation of doxorubicin was achieved by peptideconjugated PLGA-PEG nanoparticles.

\section{Acknowledgments}

This work was supported by the National Science Council in Taiwan (NSC 99-2320-B-002-021-MY3). The authors appreciate the kind assistance of Professor Fu Hsiung Chang from the Graduate Institute of Biochemistry and Molecular Biology, College of Medicine, National Taiwan University in Taiwan, in the particle size analysis.

\section{Disclosure}

The authors report no conflict of interest in this work.

\section{References}

1. Lu JM, Wang X, Marin-Muller C, et al. Current advances in research and clinical applications of PLGA-based nanotechnology. Expert Rev Mol Diagn. 2009;9:325-341.

2. Semete B, Booysen L, Lemmer Y, et al. In vivo evaluation of the biodistribution and safety of PLGA nanoparticles as drug delivery systems. Nanomedicine. 2010;6:662-671.

3. Jain RA. The manufacturing techniques of various drug loaded biodegradable poly(lactide-co-glycolide) (PLGA) devices. Biomaterials. 2000;21: 2475-2490.

4. Lim TY, Poh CK, Wang W. Poly (lactic-co-glycolic acid) as a controlled release delivery device. J Mater Sci Mater Med. 2009;20:1669-1675.

5. Du L, Mei X, Wang C, Li X, Zhang F, Jin Y. In-vitro/in-vivo studies of the biodegradable poly-(D,L-lactide-co-glycolide) microspheres of a novel luteinizing hormone-releasing hormone antagonist for prostate cancer treatment. Anticancer Drugs. 2011;22:262-272.

6. Grabrucker AM, Garner CC, Boeckers TM, et al. Development of novel $\mathrm{Zn}$ loaded nanoparticles designed for cell-type targeted drug release in CNS neurons: in vitro evidences. PLoS One. 2011;6:e17851. 
7. Ranganath SH, Fu Y, Arifin DY, et al. The use of submicron/nanoscale PLGA implants to deliver paclitaxel with enhanced pharmacokinetics and therapeutic efficacy in intracranial glioblastoma in mice. Biomaterials. 2010;31:5199-5207.

8. Avgoustakis K. Pegylated poly(lactide) and poly(lactide-co-glycolide) nanoparticles: preparation, properties and possible applications in drug delivery. Curr Drug Deliv. 2004;1:321-333.

9. Betancourt T, Byrne JD, Sunaryo, N, et al. PEGylation strategies for active targeting of PLA/PLGA nanoparticles. J Biomed Mater Res A. 2009;91:263-276.

10. Gref R, Luck M, Quellec P, et al. 'Stealth' corona-core nanoparticles surface modified by polyethylene glycol (PEG): influences of the corona (PEG chain length and surface density) and of the core composition on phagocytic uptake and plasma protein adsorption. Colloids Surf B Biointerfaces. 2000;18:301-313.

11. Ding H, Yong KT, Roy I, et al. Bioconjugated PLGA-4-arm-PEG branched polymeric nanoparticles as novel tumor targeting carriers. Nanotechnology. 2011;22:165101.

12. Dhar S, Kolishetti N, Lippard SJ, Farokhzad OC. Targeted delivery of a cisplatin prodrug for safer and more effective prostate cancer therapy in vivo. Proc Natl Acad Sci US A. 2011;108:1850-1855.

13. Moghimi SM, Hunter AC, Murray JC. Long-circulating and targetspecific nanoparticles: theory to practice. Pharmacol Rev. 2001;53: 283-318.

14. Avgoustakis K, Beletsi A, Panagi Z, et al. Effect of copolymer composition on the physicochemical characteristics, in vitro stability, and biodistribution of PLGA-mPEG nanoparticles. Int J Pharm. 2003;259:115-127.

15. Sledge GW, Miller KD Jr. Exploiting the hallmarks of cancer: the future conquest of breast cancer. Eur J Cancer. 2003;39:1668-1675.

16. Teicher BA. Molecular targets and cancer therapeutics: discovery, development and clinical validation. Drug Resist Updat. 2000;3:67-73.

17. Maeda H. Tumor-selective delivery of macromolecular drugs via the EPR effect: background and future prospects. Bioconjug Chem. 2010;21:797-802.

18. Maeda H, Wu J, Sawa T, Matsumura Y, Hori K. Tumor vascular permeability and the EPR effect in macromolecular therapeutics: a review. $J$ Control Release. 2000;6:271-284.

19. Matsumura Y, Maeda H. A new concept for macromolecular therapeutics in cancer chemotherapy: mechanism of tumoritropic accumulation of proteins and the antitumor agent Smancs. Cancer Res. 1986;46: 6387-6392.

20. Nakanishi T, Fukushima S, Okamoto K, et al. Development of the polymer micelle carrier system for doxorubicin. J Control Release. 2001;74:295-302.

21. Tobio M, Gref R, Sanchez A, Langer R, Alonso MJ. Stealth PLA-PEG nanoparticles as protein carriers for nasal administration. Pharm Res. $1998 ; 15: 270-275$

22. Zhao H, Yung LY. Selectivity of folate conjugated polymer micelles against different tumor cells. Int J Pharm. 2008;349:256-268.

23. Farokhzad OC, Jon S, Khademhosseini A, Tran TN, Lavan DA, Langer R. Nanoparticle-aptamer bioconjugates: a new approach for targeting prostate cancer cells. Cancer Res. 2004;64:7668-7672.

24. Cheng J, Teply BA, Sherifi I, et al. Formulation of functionalized PLGAPEG nanoparticles for in vivo targeted drug delivery. Biomaterials. 2007;28:869-876

25. Farokhzad OC, Cheng J, Teply BA, et al. Targeted nanoparticle-aptamer bioconjugates for cancer chemotherapy in vivo. Proc Natl Acad Sci US A. 2006;103:6315-6320.

26. Esmaeili F, Ghahremani MH, Ostad SN, et al. Folate-receptor-targeted delivery of docetaxel nanoparticles prepared by PLGA-PEG-folate conjugate. J Drug Target. 2008;16:415-423.

27. Lee $\mathrm{H}, \mathrm{Hu}$ M, Reilly RM, Allen C. Apoptotic epidermal growth factor (EGF)-conjugated block copolymer micelles as a nanotechnology platform for targeted combination therapy. Mol Pharm. 2007;4: 769-781.
28. Acharya S, Dilnawaz F, Sahoo SK. Targeted epidermal growth factor receptor nanoparticle bioconjugates for breast cancer therapy. Biomaterials. 2009;30:5737-5750.

29. Zhang N, Chittasupho C, Duangrat C, Siahaan TJ, Berkland C. PLGA nanoparticle-peptide conjugate effectively targets intercellular celladhesion molecule-1. Bioconjug Chem. 2008;19:145-152.

30. Moriya T, Kanomata N, Kozuka Y, et al. Molecular morphological approach to the pathological study of development and advancement of human breast cancer. Med Mol Morphol. 2010;43:67-73.

31. Alshenawy HA. Immunohistochemical expression of epidermal growth factor receptor, E-cadherin, and matrix metalloproteinase-9 in ovarian epithelial cancer and relation to patient deaths. Ann Diagn Pathol. 2010;14:387-395.

32. Simonetti S, Molina MA, Queralt C, et al. Detection of EGFR mutations with mutation-specific antibodies in stage IV non-small-cell lung cancer. Transl Med. 2010;8:135.

33. Pal SK, Figlin RA, Reckamp K. Targeted therapies for non-small cell lung cancer: an evolving landscape. Mol Cancer Ther. 2010;9: 1931-1944.

34. Kolonin MG, Bover L, Sun J, et al. Ligand-directed surface profiling of human cancer cells with combinatorial peptide libraries. Cancer Res. 2006;66:34-40.

35. Harris RC, Chung E, Coffey RJ. EGF receptor ligands. Exp Cell Res. 2003;284:2-13.

36. Tarasevich BJ, Gutowska A, Li XS, Jeong BM. The effect of polymer composition on the gelation behavior of PLGA-g-PEG biodegradable thermoreversible gels. J Biomed Mater Res A. 2009;89:248-254.

37. Ghahremankhani AA, Dorkoosh F, Dinarvand R. PLGA-PEG-PLGA tri-block copolymers as in situ gel-forming peptide delivery system: effect of formulation properties on peptide release. Pharm Dev Technol. 2008;13:49-55.

38. Goddard ED, Turro NJ, Kuo PL, Ananthapadmanabhan KP. Fluorescence probes for critical micelle concentration determination. Langmuir. 1985; 1:352-355.

39. Lin WJ, Chen MH. Synthesis of multifunctional chitosan with galactose as a targeting ligand for glycoprotein receptor. Carbohydr Polym. 2007;67:474-480

40. Yin Y, Chen D, Qiao M, Wei X, Hu H. Lectin-conjugated PLGA nanoparticles loaded with thymopentin: ex vivo bioadhesion and in vivo biodistribution. J Control Release. 2007;123:27-38.

41. Davaran S, Rashidi MR, Pourabbas B, Dadashzadeh M, Haghshenas NM. Adriamycin release from poly(lactide-coglycolide)-polyethylene glycol nanoparticles: synthesis, and in vitro characterization. Int $J$ Nanomedicine. 2006;1:535-539.

42. Ciapetti G, Cenni E, Pratelli L, Pizzoferrato A. In vitro evaluation of cell/biomaterial interaction by MTT assay. Biomaterials. 1993;14: 359-364.

43. Campos-Lara M, Mendoza-Espinoza JA. Cytotoxic evaluation of fluvastatin and rosuvastatin and effect of fluvastatin in the HeLa cell cycle. Afr J Pharm Pharmacol. 2011;5:322-326.

44. Chittasupho C, Xie SX, Baoum A, Yakovleva T, Siahaan TJ, Berkland CJ. ICAM-1 targeting of doxorubicin-loaded PLGA nanoparticles to lung epithelial cells. Eur J Pharm Sci. 2009;37:141-150.

45. Jin C, Qian N, Zhao W, et al. Improved therapeutic effect of DOX-PLGAPEG micelles decorated with bivalent fragment HAb18 F(ab')(2) for hepatocellular carcinoma. Biomacromolecules. 2010;11:2422-2431.

46. Yadav AK, Mishra P, Mishra AK, Mishra P, Jain S, Agrawal GP. Development and characterization of hyaluronic acid-anchored PLGA nanoparticulate carriers of doxorubicin. Nanomedicine. 2007;3: 246-257.

47. Buwalda SJ, Dijkstra PJ, Calucci L, Forte C, Feijen J. Influence of amide versus ester linkages on the properties of eight-armed PEG-PLA star block copolymer hydrogels. Biomacromolecules. 2010;11:224-232.

48. Lee ES, Oh KT, Kim D, Youn YS, Bae YH. Tumor pH-responsive flower-like micelles of poly(L-lactic acid)-b-poly(ethylene glycol)-bpoly(L-histidine). J Control Release. 2007;123:19-26. 
49. Kim SY, Shin IG, Lee YM, Cho CS, Sung YK. Methoxy poly(ethylene glycol) and epsilon-caprolactone amphiphilic block copolymeric micelle containing indomethacin. II. Micelle formation and drug release behaviours. J Control Release. 1998;51:13-22.

50. Ioele G, Cione E, Risoli A, Genchi G, Ragno G. Accelerated photostability study of tretinoin and isotretinoin in liposome formulations. Int J Pharm. 2005;293:251-260.

51. van Vlerken LE, Duan Z, Little SR, Seiden MV, Amiji MM. Biodistribution and pharmacokinetic analysis of paclitaxel and ceramide administered in multifunctional polymer-blend nanoparticles in drug resistant breast cancer model. Mol Pharm. 2008;5:516-526.

52. Zange R, Li Y, Kissel T. Biocompatibility testing of ABA triblock copolymers consisting of poly(L-lactic-co-glycolic acid) A blocks attached to a central poly(ethylene oxide) B block under in vitro conditions using different L929 mouse fibroblasts cell culture models. J Control Release. 1998;56:249-258.

53. Singh A, Wilczynski A, Holder JR, et al. Incorporation of a bioactive reverse-turn heterocycle into a peptide template using solid-phase synthesis to probe melanocortin receptor selectivity and ligand conformations by 2D ${ }^{1} \mathrm{H}$ NMR. J Med Chem. 2011;54:1379-1390.

54. Milane L, Duan Z, Amiji M. Development of EGFR-targeted polymer blend nanocarriers for combination paclitaxel/lonidamine delivery to treat multi-drug resistance in human breast and ovarian tumor cells. Mol Pharm. 2011;8:185-203.
55. Yousefpour P, Atyabi F, Vasheghani-Farahani E, Movahedi AA Dinarvand R. Targeted delivery of doxorubicin-utilizing chitosan nanoparticles surface-functionalized with anti-Her2 trastuzumab. Int J Nanomedicine. 2011;6:1977-1990.

56. Khoee S, Rahmatolahzadeh R. Synthesis and characterization of $\mathrm{pH}$ responsive and folated nanoparticles based on self-assembled brush-like PLGA/PEG/AEMA copolymer with targeted cancer therapy properties: a comprehensive kinetic study. Eur J Med Chem. 2012;50:416-427.

57. Gillies ER, Fréchet JM. pH-responsive copolymer assemblies for controlled release of doxorubicin. Bioconjug Chem. 2005;16:361-368.

58. Unger F, Wittmar M, Morell F, Kissel T. Branched polyesters based on poly[vinyl-3-(dialkylamino)alkylcarbamate-co-vinyl acetateco-vinyl alcohol]-graft-poly (D,L-lactide-co-glycolide): effects of polymer structure on in vitro degradation behaviour. Biomaterials. 2008;29:2007-2014.

59. Xue HY, Wong HL. Tailoring nanostructured solid-lipid carriers for time-controlled intracellular siRNA kinetics to sustain RNAi-mediated chemosensitization. Biomaterials. 2011;32:2662-2672.

60. Manchun S, Dass CR, Sriamornsak P. Targeted therapy for cancer using pH-responsive nanocarrier systems. Life Sci. 2012;90:381-387.

61. Han HD, Lee A, Hwang T, et al. Enhanced circulation time and antitumor activity of doxorubicin by comblike polymer-incorporated liposomes. J Control Release. 2007;120:161-168.
International Journal of Nanomedicine

\section{Publish your work in this journal}

The International Journal of Nanomedicine is an international, peerreviewed journal focusing on the application of nanotechnology in diagnostics, therapeutics, and drug delivery systems throughout the biomedical field. This journal is indexed on PubMed Central,

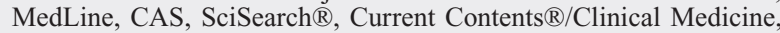

\section{Dovepress}

Journal Citation Reports/Science Edition, EMBase, Scopus and the Elsevier Bibliographic databases. The manuscript management system is completely online and includes a very quick and fair peer-review system, which is all easy to use. Visit http://www.dovepress.com/ testimonials.php to read real quotes from published authors. 